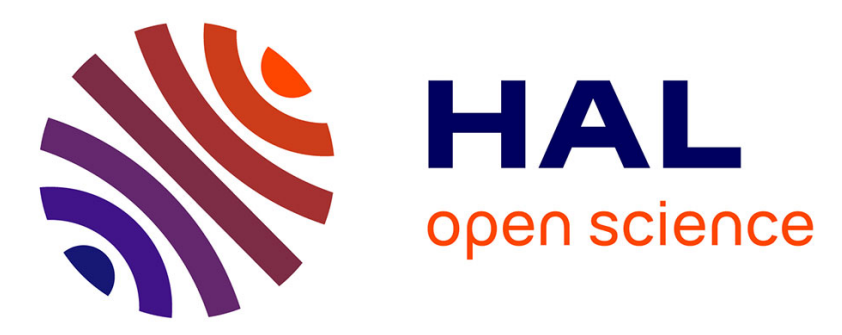

\title{
Varying dependency of periplasmic peptidyl-prolyl cis/trans isomerases in promoting Yersinia pseudotuberculosis stress tolerance and pathogenicity
}

Ikenna R Obi, Roland Nordfelth, Matthew S Francis

\section{- To cite this version:}

Ikenna R Obi, Roland Nordfelth, Matthew S Francis. Varying dependency of periplasmic peptidylprolyl cis/trans isomerases in promoting Yersinia pseudotuberculosis stress tolerance and pathogenicity. Biochemical Journal, 2011, 439 (2), pp.321-332. 10.1042/BJ20110767 . hal-00628676

\section{HAL Id: hal-00628676 https://hal.science/hal-00628676}

Submitted on 4 Oct 2011

HAL is a multi-disciplinary open access archive for the deposit and dissemination of scientific research documents, whether they are published or not. The documents may come from teaching and research institutions in France or abroad, or from public or private research centers.
L'archive ouverte pluridisciplinaire HAL, est destinée au dépôt et à la diffusion de documents scientifiques de niveau recherche, publiés ou non, émanant des établissements d'enseignement et de recherche français ou étrangers, des laboratoires publics ou privés. 


\title{
Varying dependency of periplasmic peptidyl-prolyl cis/trans isomerases in promoting Yersinia pseudotuberculosis stress tolerance and pathogenicity
}

\author{
Ikenna R. Obi, Roland Nordfelth and Matthew S. Francis ${ }^{\S}$ \\ Department of Molecular Biology and Umeå Center for Microbial Research, Umeå University, \\ SE-901 87 Umeå, Sweden
}

Short title: Periplasmic PPIases from Yersinia

Abbreviations used: PPIase(s), periplasmic peptidyl-prolyl cis/trans isomerase(s); ROIs, reactive oxygen intermediates; ID $50,50 \%$ infectious dose; LPS, lipopolysaccharide; CsA, cyclosporin A; FKBP, FK506 binding proteins; YSA, Yersinia selective agar; SDS, sodium dodecyl sulfate; CFU, colony forming units; IPTG, Isopropyl- $\beta$-D-thio-galactoside; MALDI-TOF, Matrix assisted laser desorption ionization time of flight mass spectrometry; FA, fatty acids; PE, phosphatidylethanolamine; PG, phosphatidylglycerol; CL, cardiolipin.

$\S$ To whom correspondence should be addressed: Department of Molecular Biology, Umeå University, SE-901 87 Umeå, Sweden. Phone: +46-(0)90-7856752; Fax +46-(0)90-772630; Email: matthew.francis@molbiol.umu.se 


\section{SYNOPSIS}

Periplasmic peptidyl-prolyl cis/trans isomerases (PPIases) catalyze the cis/trans isomerization of peptidyl-prolyl bonds, which is a rate-limiting step during protein folding. We demonstrate that the surA, ppiA, ppiD fkpA and $f k l B$ alleles each encode a periplasmic PPIase in the bacterial pathogen Yersinia pseudotuberculosis. Of these, four were purified to homogeneity. Purified SurA, FkpA and FklB, but not PpiD, displayed detectable PPIase activity in vitro. Significantly, only Y. pseudotuberculosis lacking surA caused drastic alterations to the outer membrane protein profile and fatty acid composition. They also exhibited aberrant cellular morphology, leaking LPS into the extracellular environment. The SurA PPIase is therefore most critical for maintaining $Y$. pseudotuberculosis envelope integrity during routine culturing. On the other hand, bacteria lacking either surA or all of the genes ppiA, ppiD, fkpA and $f k l B$, were sensitive to hydrogen peroxide and were attenuated in mice infections. Thus, Y. pseudotuberculosis exhibits both SurA-dependent and SurA-independent requirements for periplasmic PPIase activity to ensure in vivo survival and a full virulence effect in a mammalian host.

Key words: membrane biogenesis, chaperone, protein folding, immunosuppressant, survival, infection. 


\section{INTRODUCTION}

PPIases catalyze the cis/trans isomerization of peptidyl-prolyl bonds in peptide and protein substrates [1, 2]. Isomerization of proline residues is a rate-limiting step in protein folding, underlying the ubiquitous presence of PPIases in all kingdoms of life and in different cellular compartments [2]. Three major classes of PPIases exist: the Cyclophilins, which bind the cyclosporin A (CsA) immunosuppressive drug; the FK506 binding proteins (FKBP), which bind the FK506 immunosuppressant; and the PPIases that have sequence similarity with Parvulin from the E. coli cytoplasm [1,2].

The bacterial periplasm contains all three PPIase classes. In E. coli, four definitive periplasmic PPIases have been described; SurA, PpiA, PpiD and FkpA [3, 4]. Another newly identified PPIase is denoted FklB, and might constitute the newest member of the periplasmic PPIase family [5]. SurA and PpiD belong to the Parvulin class of PPIases; PpiA is a Cyclophilin, while FkpA and FklB are related to the FKBP family. SurA is well studied; most bacteria lacking surA are more susceptible to detergents, antibiotics and hydrophobic dyes suggestive of a compromised outer membrane barrier function (reviewed in [6]). On the other hand, in vitro phenotypic defects in bacteria lacking the other periplasmic PPIases are seldom reported.

Yersinia pseudotuberculosis is an environmental bacterium associated with sporadic enteric disease outbreaks known as yersiniosis caused by the ingestion of contaminated food or fluids [7]. While this disease causes gastrointestinal discomfort, it is usually self-limiting and rarely associated with systemic disease. It is also a close relative of another enteric pathogen $Y$. enterocolitica [7] as well as the infamous plague-causing pathogen $Y$. pestis [8].

In this study, in silico analysis revealed all these five putative periplasmic PPIases in the $Y$. pseudotuberculosis YPIII genome sequence (US DOE Joint Genome Institute; GenBank accession number is CP000950) based on their amino acid sequence identity to their homologues in E. coli K12 [9]. We purified SurA, PpiD, FkpA and FklB and performed a subsequent biochemical analysis of their PPIase activity. Furthermore, we created cumulative in cis deletions of the 5 periplasmic PPIase genes in Y. pseudotuberculosis and examined their contribution to envelope integrity and survival during exposure to extracytoplasmic stress, reactive oxygen intermediates (ROIs), low $\mathrm{pH}$ and in vivo mouse infections.

\section{EXPERIMENTAL}

\section{Bacterial strains and plasmids}

The bacterial strains and plasmids used in this study are shown in Table 1.

\section{Growth conditions}

Unless stated otherwise, bacteria were cultivated routinely in Luria-Bertani (LB) agar or broth at either $26^{\circ} \mathrm{C}$ (Y. pseudotuberculosis) or $37^{\circ} \mathrm{C}$ (E. coli) with aeration. When required, antibiotics were used at the following final concentration: $50 \mu \mathrm{g} / \mathrm{mL}$ kanamycin, $25 \mu \mathrm{g} / \mathrm{mL}$ chloramphenicol and $100 \mu \mathrm{g} / \mathrm{mL}$ carbenicillin.

To assay for the viability of PPIase mutants in the presence of bile salts or detergents, overnight cultures of $Y$. pseudotuberculosis grown in LB broth at $26{ }^{\circ} \mathrm{C}$ were sub-cultured $(0.1$ volume) into $3 \mathrm{~mL}$ fresh media. The bacteria were allowed to grow for a further $2 \mathrm{~h}$ before being serially diluted and then plated on LB agar, Yersinia selective agar rich in bile salts (BD 
Stockholm, Sweden) or LB agar supplemented with $0.0125 \%(\mathrm{v} / \mathrm{v})$ SDS or $0.25 \%$ (v/v) sodium deoxycholate. Colony forming units (CFU) were counted after $48 \mathrm{~h}$ of growth.

An antibiotic sensitivity assay involved mixing $100 \mu \mathrm{L}$ from overnight cultures of $Y$. pseudotuberculosis with $10 \mathrm{~mL}$ molten $0.6 \%$ soft-agar that was then poured over LB agar plates. Vancomycin and bacitracin-impregnated discs (Oxoid, Hampshire, England) were then overlaid on the agar surface. After $24 \mathrm{~h}$ incubation at $26^{\circ} \mathrm{C}$, the diameter of the inhibitory zone around the discs was measured.

To assay for stationary phase survival, Y. pseudotuberculosis overnight cultures were subcultured ( 0.1 volume) into fresh LB broth and grown at $26{ }^{\circ} \mathrm{C}$ to mid-log phase. These bacteria were again back-diluted ( 0.001 volume) into $50 \mathrm{~mL}$ LB broth. During 6 days incubation, samples were taken at daily intervals, serially diluted and then plated on LB agar. CFU were determined after $48 \mathrm{~h}$.

To test sensitivity to menadione and hydrogen peroxide, Y. pseudotuberculosis overnight cultures were sub-cultured (0.005 volume) into fresh LB broth and grown at $26^{\circ} \mathrm{C}$ for $1 \mathrm{~h}$. Samples were serially diluted and then plated on LB agar supplemented with $200 \mu \mathrm{M}$ menadione or $1 \mathrm{mM}$ hydrogen peroxide. CFU were counted after $48 \mathrm{~h}$ of growth.

For the $\mathrm{pH}$ testing, overnight cultures of Yersinia were subcultured in LB broth ( 0.1 volume) buffered with $100 \mathrm{mM}$ citrate $\mathrm{pH} 3$ or $\mathrm{pH}$ 5. Bacteria were grown at 26 for 6 hours. Samples were taken at 0,3 and 6 hours. After serial dilution, samples were plated on LB-agar. CFU were counted after 48 hours. LB broth buffered with $20 \mathrm{mM}$ potassium phosphate $\mathrm{pH} 7$ was used as a control.

\section{Generation of mutants}

Overlap PCR with template DNA from Y. pseudotuberculosis YPIII/pIB102 was used to generate mutated alleles for constructing the full-length in-frame deletion mutants. The primer pairs used to generate each mutation are listed in Supplementary Table S1. Amplified fragments

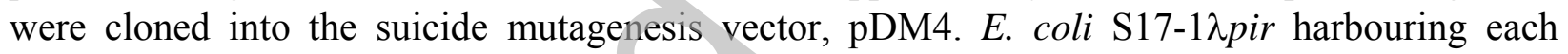
specific mutagenesis vector was used in conjugal mating experiments with $Y$. pseudotuberculosis. Selection for the appropriate allelic exchange events giving rise to the desired $Y$. pseudotuberculosis mutants used our conventional sucrose sensitivity methodology $[10]$.

\section{Over-expression and purification of recombinant PPIases}

PPIase genes were PCR amplified from the Y. pseudotuberculosis YPIII/pIB102 genome using the primer pairs listed in Supplementary Table S1. Codons 2 to 105 of ppiD were omitted to avoid sequences encoding for a putative trans-membrane region. The DNA fragments were cloned in pET30a $(+)$ (Novagen) generating PPIase gene sequences in frame with the 5' His-tag resident in the plasmid. Recombinant PPIases were over-expressed in E. coli BL21 grown to logarithmic phase $\left(\mathrm{OD}_{600}\right.$ of 0.5$)$ in $250 \mathrm{~mL}$ of LB broth. Upon addition of $0.4 \mathrm{mM}$ IPTG bacteria were cultured for a further $3 \mathrm{~h}$. Bacteria were washed with $50 \mathrm{~mL}$ lysis buffer $(20 \mathrm{mM}$ Tris- $\mathrm{HCl}, \mathrm{pH} 7.5,500 \mathrm{mM} \mathrm{NaCl}, 30 \mathrm{mM}$ Imidazole) and concentrated 10-fold in this buffer containing lysozyme $(1 \mathrm{mg} / \mathrm{ml})$. Afterwards, bacteria were lysed by sonication and soluble lysates clarified by centrifugation $(32,000 \mathrm{~g}, 1 \mathrm{~h})$ and passaged through a $0.2 \mu \mathrm{m}$ filter prior to protein purification by affinity chromatography on $\mathrm{Ni}^{2+}$ agarose columns (GE Healthcare, Sweden) using the AKTA purifier (GE Healthcare). Columns were washed with $50 \mathrm{~mL}$ lysis buffer and the proteins eluted with $20 \mathrm{mM}$ Tris- $\mathrm{HCl}, \mathrm{pH} 7.5,500 \mathrm{mM} \mathrm{NaCl}, 1 \mathrm{M}$ Imidazole using 
a linear gradient. Pooled eluted fractions were dialyzed overnight against $20 \mathrm{mM}$ Tris- $\mathrm{HCl} \mathrm{pH} 8$, $50 \mathrm{mM} \mathrm{NaCl}$. Protein purity was assessed by SDS-PAGE and Coomassie Blue staining. Protein concentration was determined using BCA protein assay kit (Pierce, Rockford, USA).

\section{PPIase assay}

The PPIase activity was performed in $50 \mathrm{mM}$ Tris- $\mathrm{HCl}, \mathrm{pH} 8$ at $10{ }^{\circ} \mathrm{C}$ using the proteasecoupled assay [11]. The peptide substrate, Suc-Ala-Leu-Pro-Phe-pNa, was purchased from Bachem (Switzerland). Nitroaniline appearance due to $\alpha$-chymotrypsin cleavage of the peptide trans-isomer was followed at $390 \mathrm{~nm}$ for $3 \mathrm{~min}$ with a Beckman Coulter DU 730 Life Science UV/Vis spectrophotometer. First-order rate constants $\left(\mathrm{k}_{\mathrm{obs}}\right)$ were derived by fitting reaction progress-curves to a first-order rate equation $\left(\mathrm{y}_{390}=\mathrm{y}_{0}+\mathrm{a}\left(1-\mathrm{e}^{-\mathrm{kt}}\right)\right.$, where $\mathrm{k}$ is the rate constant, $\mathrm{y}_{0}$ is the absorbance at time 0$) . \mathrm{k}_{\text {cat }} / \mathrm{K}_{\mathrm{m}}$ was calculated from the plot of $\mathrm{k}_{\mathrm{obs}}$ versus PPIase concentration.

The PPIase inhibition assay used stock solutions of each immunosuppressant CsA, FK506 or rampamycin (LC laboratories, Massachusetts) prepared in ethanol/water $(1: 1, \mathrm{v} / \mathrm{v})$. PPIases $(0.1$ $\mu \mathrm{M}$ ) were incubated with various concentrations of drug on ice for $7 \mathrm{~min}$ prior to PPIase activity measurements. The respective rate constants in the presence of the inhibitors were derived by fitting reaction progress-curves to the first-order rate equation.

\section{Whole bacterial lysates and cellular fractionation}

To prepare whole bacterial cell lysates, overnight cultures of $Y$. pseudotuberculosis were grown at $26{ }^{\circ} \mathrm{C}$ and $37{ }^{\circ} \mathrm{C}$. After standardization of the optical density at $600 \mathrm{~nm}$ and centrifugation (5,000 g, $10 \mathrm{~min})$, cells were lysed in SDS sample buffer (50 mM Tris-HCl, $\mathrm{pH}$ 6.8, 2 \% SDS, 10 $\%$ glycerol, $5 \% \beta$-mercaptoethanol and $0.1 \%$ bromophenol blue) and heat inactivated.

For fractionation experiments, bacteria grown to logarithmic phase in $200 \mathrm{~mL} \mathrm{LB}$ broth at 26 ${ }^{\circ} \mathrm{C}$ were resuspended in $30 \mathrm{mM}$ Tris- $\mathrm{HCl}, \mathrm{pH} 8,20 \%$ sucrose at $80 \mathrm{~mL}$ per gram wet weight. After addition of $500 \mathrm{mM}$ EDTA drop wise to an end concentration of $1 \mathrm{mM}$ and a $10 \mathrm{~min}$ incubation on ice with gentle agitation, cells were harvested $\left(8,000 \mathrm{~g}, 20 \mathrm{~min}, 4{ }^{\circ} \mathrm{C}\right)$ and the pellet resuspended in $500 \mu \mathrm{L}$ of ice-cold $5 \mathrm{mM} \mathrm{MgSO}_{4}$. Following agitation for $1 \mathrm{~h}$ at $4{ }^{\circ} \mathrm{C}$, the periplasmic fraction (supernatant) was collected $(8,000 \mathrm{~g}, 20 \mathrm{~min}$ ) and subsequently mixed with SDS sample buffer. The pellet was resuspended in $500 \mu \mathrm{L} 100 \mathrm{mM}$ Tris-HCl, pH $8,10 \mathrm{mM}$ EDTA and the osmotic-shocked cells were lysed by three freeze-thaw cycles and a 1 min sonication. The cytoplasmic fraction (supernatant) was recovered (22,000 g, $30 \mathrm{~min}$ ) and mixed with SDS sample buffer. The remaining pellet (crude membrane fraction) was washed with 500 $\mu \mathrm{L} 20 \mathrm{mM} \mathrm{K}_{2} \mathrm{PO}_{4}(\mathrm{pH}$ 7). To separate inner membrane from outer membrane, the pellet was resuspended in $100 \mu \mathrm{L}$ of $0.5 \%$ sarcosyl in $20 \mathrm{mM} \mathrm{K}_{2} \mathrm{PO}_{4}(\mathrm{pH} \mathrm{7})$. After incubation at room temperature for $30 \mathrm{~min}$, the inner membrane (soluble fraction) was collected $(22,000 \mathrm{~g})$ and treated with SDS sample buffer. The outer membrane (pellet) was washed once with $100 \mu \mathrm{L}$ $0.5 \%$ sarcosyl in $20 \mathrm{mM} \mathrm{K}_{2} \mathrm{PO}_{4}(\mathrm{pH} \mathrm{7})$ and resuspended in SDS sample buffer. Following separation by $12 \%$ SDS-PAGE, proteins were transferred to PVDF membrane (Millipore, Bedford, USA) and identified with rabbit polyclonal antibodies raised against individually purified recombinant PPIase proteins (Agrisera $\mathrm{AB}$, Vännäs, Sweden) as approved by the Animal Ethics Committee of Umeå University (ethics number A102/09).

\section{Mass spectrometry and protein identification}


Sample preparation, mass spectrometry and protein identification was based on previously described procedures [12]. A protein ID was considered valid if it was top-most on the putative hit list generated by the MASCOT search engine (http:/www.matrixscience.com) and with a probability based Mowse score above the significance threshold $(\mathrm{p}<0.05$; vide infra).

\section{Isolation of LPS}

To isolate LPS liberated free from Y. pseudotuberculosis grown overnight in $200 \mathrm{~mL}$ LB broth at $26{ }^{\circ} \mathrm{C}$, we adapted a method for outer membrane vesicle purification [13] by including a terminal proteinase $\mathrm{K}$ digestion step. Briefly, to pellets resuspended in $20 \mathrm{mM}$ Tris- $\mathrm{HCl}$, pH 8, SDS was added to a final concentration of $0.1 \%$ and samples were heated for 3 min at $95^{\circ} \mathrm{C}$ to denature proteins. Final concentrations of $5 \mathrm{mM} \mathrm{CaCl}_{2}$ and $7 \mu \mathrm{g}$ proteinase $\mathrm{K}$ were added and the samples incubated overnight at $37{ }^{\circ} \mathrm{C}$. Following treatment with sample buffer, isolated LPS were analyzed by $13.5 \%$ SDS-PAGE and silver staining (Fermentas Life Sciences).

Crude total cellular LPS was prepared from stationary phase $Y$. pseudotuberculosis grown in LB broth at $26^{\circ} \mathrm{C}$. Bacterial pellets were collected by brief centrifugation, resuspended in sample buffer and lysed at $95{ }^{\circ} \mathrm{C}$ for $10 \mathrm{~min}$. Final concentrations of $5 \mathrm{mM} \mathrm{CaCl}_{2}$ and $7 \mu \mathrm{g}$ proteinase $\mathrm{K}$ were added and the samples incubated overnight at $37^{\circ} \mathrm{C}$. LPS analysis was performed by 13.5 $\%$ SDS-PAGE and silver staining.

\section{Isolation and characterization of cellular fatty acids and phospholipids}

The analysis of fatty acid and phospholipid composition of $Y$. pseudotuberculosis YPIII was performed commercially within the quality assured laboratories at Mylnefield Lipid Analysis (Dundee, UK) essentially using the method of Folch et al [14].

\section{Transmission electron microscopy (TEM)}

$Y$. pseudotuberculosis was harvested from LA plates after $48 \mathrm{~h}$. Bacteria were resuspended in 10 $\mathrm{mM}$ Tris- $\mathrm{HCl}$ buffer, $\mathrm{pH} \mathrm{7.4,} 10 \mathrm{mM} \mathrm{MgCl}$ and allowed to adhere to formvar-coated grids for 3 min at room temperature. Following negative staining with $1 \%$ sodiumsilicotungstate, images of bacteria were acquired using a Jeol JEM 1230 electron microscope at 40,000x magnification.

\section{Mouse infections}

Infections were performed in accordance with the guidelines of the Animal Ethics Committee of Umeå University (ethics number A81-08). Groups of five female BALB/c mice (Scanbur, Denmark) of similar age (8 to 9 weeks) and weight ( $\sim 18 \mathrm{~g})$, were injected intraperitoneally with $0.1 \mathrm{ml}$ of different dilutions of $Y$. pseudotuberculosis parent and mutant bacteria that had been grown overnight in LB broth at $26^{\circ} \mathrm{C}$. Pelleted bacteria were serially diluted to $10^{7}, 10^{6}$ and $10^{5}$ $\mathrm{CFU} / \mathrm{ml}$ in PBS. Infection was monitored for 14 days post-injection. The $50 \%$ infectious dose $\left(\mathrm{ID}_{50}\right)$ was determined by the Reed-Muench method [15], with positivity of infection reflected by symptoms of ruffled fur, weight loss, listlessness and diarrhoea. Infected mice showing symptoms of a terminal infection were immediately euthanized.

\section{RESULTS}

\section{Identification of $Y$. pseudotuberculosis periplasmic PPIases}

Amino acid sequence alignments with their homologues in E. coli K12 revealed five potential periplasmic PPIases in the $Y$. pseudotuberculosis YPIII genome: surA (NCBI annotation 
YPK_3571), ppiD (YPK_3230), ppiA (YPK_0242), fkpA (YPK_0270), and fklB (YPK_3778) (Figure 1A). Their amino acid sequences were at least $99 \%$ identical to their homologues in $Y$. pestis, between 85 to $98 \%$ in Y. enterocolitica and 58 to $79 \%$ in E. coli (Figure 1B). Based upon BLAST motif searches (Figure 1C), SurA (434 amino acids) is comprised of four domains: a unique N-terminal domain, two Parvulin domains and a C-terminal domain possessing an unknown fold. PpiD (628 amino acids) contains three domains: a trans-membrane domain, an Nterminal domain that is similar to that of SurA, and a Parvulin domain. In addition, the protein contains a long C-terminal region of unknown fold. PpiA (189 amino acids) possesses a Cyclophilin domain, while FkpA (266 amino acids) and FklB (206 amino acids) consist of two domains: $\mathrm{N}$ - and a $\mathrm{C}$-terminal domain both displaying (FKBP) consensus.

\section{Production and purification of $Y$. pseudotuberculosis periplasmic PPIases}

surA, ppiA, ppiD, fkpA and $f k l B$ genes were PCR amplified from $Y$. pseudotuberculosis YPIII/pIB102 genome and cloned into pET-30a(+). IPTG induction of protein expression in $E$. coli BL21 cells resulted in soluble forms of recombinant SurA, PpiD, FkpA and Fk1B, whereas PpiA was produced as an insoluble protein (data not shown). Varying IPTG concentration or induction temperature did not improve the solubility of recombinant PpiA (data not shown). Soluble forms of SurA, PpiD, FkpA and FklB were purified from E. coli cell-lysates using nickel affinity chromatography and protein purity was analyzed by SDS-PAGE (Figure 2). This onestep purification process provided very pure protein that migrated to about $52 \mathrm{kDa}, 74 \mathrm{kDa}, 33$ $\mathrm{kDa}$ and $27 \mathrm{kDa}$ on SDS-PAGE, corresponding to the apparent molecular masses of recombinant SurA, PpiD, FkpA and FklB, respectively. Protein yield of about $3 \mathrm{mg}$ was obtained from a 250 $\mathrm{mL}$ culture for each protein.

\section{SurA, FkpA and FklB exhibit detectable PPIase activity}

Having purified recombinant SurA, PpiD, FkpA and FklB, we performed a rarely executed comparative assessment of their individual PPIase activity using a $\alpha$-chymotrypsin-coupled spectrophotometric assay that monitors the cis/trans isomerization of the peptidyl-prolyl bond in the tetrapeptide Suc-Ala-Leu-Pro-Phe-pNa. This assay is based on the fact that $\alpha$-chymotrypsin can hydrolyze the 4-nitroanilide amide bond in the tetrapeptide only when the Leu-Pro bond is in the trans-conformation. SurA, FkpA and FklB displayed PPIase activity (Figure 3A). No detectable activity was observed with PpiD, consistent with an earlier report concerning E. coli PpiD [16] or for the two-component response regulator, $\mathrm{CpxR}$, which was used as a negative control (Figure 3A). SurA PPIase activity was low in comparison to the robust activity of FkpA and FklB. The lower intrinsic SurA PPIase activity has also been observed for E. coli SurA [17, 18]. Furthermore, the PPIase activity of SurA, FkpA and FklB was concentration dependent (Figure 3B). Under our assay conditions, the catalytic efficiencies $\left(\mathrm{k}_{\mathrm{cat}} / \mathrm{K}_{\mathrm{m}}\right)$ of FklB $\left(1.1 \times 10^{6} \mathrm{M}^{-}\right.$ $\left.{ }^{1} \mathrm{~s}^{-1}\right)$ was highest, followed by that of FkpA $\left(2.6 \times 10^{5} \mathrm{M}^{-1} \mathrm{~s}^{-1}\right)$, whereas SurA $\left(4.7 \times 10^{4} \mathrm{M}^{-1} \mathrm{~s}^{-1}\right)$ has the least specificity for the tetrapeptide substrate. FklB and FkpA catalytic efficiencies are comparable to other biochemically verified FKBPs $[19,20]$.

To confirm the presence of an intrinsic PPIase activity in the $Y$. pseudotuberculosis periplasm, we isolated periplasmic extracts from the parental bacteria and a quintuple mutant ( $\triangle p p i A \Delta p p i D$ $\Delta f k p A \Delta f k l B \Delta s u r A$ ) lacking the five periplasmic PPIase genes. These extracts were assayed for PPIase activity using the tetrapeptide Suc-Ala-Leu-Pro-Phe-pNa. Periplasmic extract from the parental bacteria was active in cis/trans isomerization of peptidy-prolyl bond of the tetrapeptide, whereas no PPIase activity was detected in the periplasmic extract of the quintuple mutant 
(Supplementary Figure S1). We therefore considered that a lack of PPIase activity in the periplasmic fraction of the $\Delta p p i A \Delta p p i D \Delta f k p A \Delta f k l B \Delta s u r A$ quintuple mutant was indicative of an important in vivo role for these periplasmic PPIases in maintaining optimal $Y$. pseudotuberculosis fitness.

\section{PPIase inhibition by immunosuppressive drugs}

PPIases were first discovered based on their high affinity to bind immunosuppressive drugs. To investigate the effects of CsA, FK506 and rampamycin immunosuppressants on SurA, FkpA and FklB, $0.1 \mu \mathrm{M}$ of protein was incubated with various concentrations of the drugs, and then assayed for remaining PPIase activity. CsA, FK506 and rampamycin showed no detectable effect on SurA PPIase activity, even at excessive concentrations $(10 \mu \mathrm{M}$ for CsA and $0.5 \mu \mathrm{M}$ for FK506 and rampamycin) (Figure 4A and data not shown). This is consistent with SurA being classified as a Parvulin-like PPIase. However, FkpA (Figure 4B) and FklB (Figure 4C) were strongly inhibited by FK506 and rampamycin in a dose-dependent manner. Rampamycin was more effective at causing complete inhibition of FkpA and FklB activity with an $\mathrm{IC}_{50}$ of $19 \mathrm{nM}$ and $51 \mathrm{nM}$, respectively; this compared to an $\mathrm{IC}_{50}$ of $43 \mathrm{nM}$ and $119 \mathrm{nM}$ needed for FK506 to inhibit FkpA and FklB activity, respectively. These data reflect the higher affinity of rampamycin to FKBPs [21]. As anticipated, CsA failed to diminish the PPIase activity of FkpA or FklB (Figure 4B and 4C).

\section{Sub-cellular localization of SurA, PpiD, FkpA and FklB in Y. pseudotuberculosis}

Protein prediction algorithms indicate the presence of signal peptides in SurA and FkpA as well as a trans-membrane domain in PpiD (data not shown). This implies that these proteins are likely to be localized in the bacterial envelope. However, no related information is available for FklB. We therefore utilized each recombinant purified PPIase as antigen to generate specific polyclonal rabbit antibodies. These were then used to experimentally analyze the sub-cellular localization of SurA, PpiD, FkpA and FklB in the same Y. pseudotuberculosis whole cell-lysate that was separated into outer membrane, periplasmic, inner membrane and cytoplasmic fractions. To control fractionation purity, TolC, MBP, FtsH and H-NS were used as outer membrane, periplasmic, inner membrane and cytoplasmic markers, respectively. All of the PPIases could be detected in the whole cell-lysate (Figure 5). SurA and FkpA were enriched in the periplasmic fraction, while PpiD was enriched in the inner membrane fraction. These data are consistent with their repesctive localizations in E. coli $[22,23]$. However, contrary to a previous study that identified FklB in the periplasm using indirect detection with the Mip antibody [5], our anti-FklB antibodies identified FkIB exclusively in the inner membrane.

\section{Peptidoglycan-associated lipoprotein (Pal) and OmpA are among several outer membrane proteins reduced in surA mutants}

In E. coli, SurA functions as a periplasmic folding factor of various outer membrane proteins (reviewed in [6]). To study effects of loss of surA on outer membrane proteins in $Y$. pseudotuberculosis, outer membrane protein profiles of parental, surA single ( $\Delta s u r A)$, quadruple $(\triangle p p i A \Delta p p i D \Delta f k p A \quad f k l B)$ and quintuple $(\Delta p p i A \Delta p p i D \Delta f k p A \Delta f k l B \Delta$ surA) deletion mutants were analyzed by SDS-PAGE and Coomassie blue staining. Indeed, the surA single and quintuple mutants showed decreased amounts of proteins in their outer membrane in comparison to the parental bacteria (Supplementary Figure S2A). This defect could be complemented by transforming these surA mutants with a low-copy plasmid expressing a wild type copy of surA 
from its native promoter. Strikingly, the $\operatorname{SurA}^{+}$quadruple mutant lacking the other four periplasmic PPIase genes exhibited the same outer membrane protein levels as the parental bacteria (Supplementary Figure S2A). To identify some of the reduced outer membrane proteins caused by surA deletion, protein bands of interest from parental bacteria were excised from the Coomassie blue-stained gel. Preliminary MALDI-TOF analysis of in-gel digested tryptic fragments identified a $18 \mathrm{kDa}$ protein as Pal (Supplementary Figure S2B) and a $36 \mathrm{kDa}$ protein as OmpA (Supplementary Figure S2C).

\section{Y. pseudotuberculosis lacking surA are leaky}

An alteration in outer membrane protein profiles suggests a compromised outer membrane. To identify if this induced morphological changes in the affected bacteria, we used TEM to visualize bacterial morphology. Parental bacteria and the quadruple mutant ( $\triangle p p i A \Delta p p i D \Delta f k p A \Delta f k l B)$ possessed a uniform peripheral exterior suggestive of an intact bacterial envelope (Figure 6A and 6D). In contrast, the surA mutants ( $\Delta$ surA or $\Delta p p i A \Delta p p i D \Delta f k p A \Delta f k l B \Delta s u r A)$ displayed an irregular surface and leak material into the surrounding milieu (Figure $6 \mathrm{~B}$ and $6 \mathrm{E}$ ). These morphological effects were due to the loss of functional surA because a normal morphology could be restored by trans-complementation with a wild type copy of surA (Figure 6C and 6F).

Despite many bacteria being known to release outer membrane blebs or vesicles, this released material is apparently not vesicular in nature because the structures lack any obvious membranous form (data not shown). To identify the nature of this liberated cellular material, cell-free bacterial supernatants were subjected to ultracentrifugation and the pelleted material collected. No obvious differences in protein content in these samples were observed (data not shown). However, following proteinase $\mathrm{K}$ digestion to remove protein material, SDS-PAGE and silver staining analysis revealed an enrichment of released LPS from the quintuple $\triangle p p i A \Delta p p i D$ $\Delta f k p A \Delta f k l B \Delta s u r A$ mutant, and to a lesser extent the single $\Delta s u r A$ mutant (Supplementary Figure $\mathrm{S} 3 \mathrm{~A}$ ). This was not observed from all other strains examined, including the trans-complemented surA mutants (Supplementary Figure S3A). Moreover, LPS discharge from the surA mutants seems to reflect a defect in LPS assembly control because total cellular LPS levels isolated from whole bacteria were indistinguishable irrespective of the strain background (Supplementary Figure S3B). It is currently unknown whether this putative LPS assembly defect is a direct or indirect consequence of SurA depletion.

\section{Deletion of surA confers altered fatty acid and phospholipid composition}

Given that $Y$. pseudotuberculosis lacking surA have reduced outer membrane protein content and possesses defects in LPS assembly, we undertook a comparative survey of the membrane fatty acid (FA) content of parental and mutant $Y$. pseudotuberculosis grown at ambient $\left(26^{\circ} \mathrm{C}\right)$ and elevated temperature $\left(37^{\circ} \mathrm{C}\right)$. This raw data can be observed in Supplementary Table S2. At $26^{\circ} \mathrm{C}$, unsaturated fatty acids (UFA) were reproducibly produced in abundance by all bacteria (62 to $67.8 \%$ of total FA), followed by saturated fatty acids (SFA) (28.8 to 32.6\%) and with minor amounts of cyclic fatty acids (CFA) (3.3 to 5.5\%) (Figure 7A, upper panel). At $37^{\circ} \mathrm{C}$, production of UFA was dramatically curtailed to between 36.7 and $48 \%$ of total FA. Interestingly, both surA mutants reproducibly produced more UFAs regardless of growth temperature. Consistent with earlier reports [24, 25], CFA production increased dramatically at $37^{\circ} \mathrm{C}$ (between 12.8 to $23 \%$; Figure $7 \mathrm{~A}$, lower panel). However, this effect was noticeably diminished in the surA mutants. The ratio of CFA produced by $Y$. pseudotuberculosis at $37^{\circ} \mathrm{C}$ compared to $26^{\circ} \mathrm{C}$ was therefore higher for $\operatorname{SurA}^{+}$bacteria than for $\mathrm{SurA}^{-}$bacteria (Figure 7B). 
On the other hand, the SFA ratios and the UFA ratios remained steady in all bacteria independent of growth temperature (Figure 7B).

A partial analysis of individual phospholipid content within whole bacteria was also determined (Supplementary Table S3). At $26^{\circ} \mathrm{C}$, phosphatidylethanolamine (PE) appeared to dominate total phospholipid content (accounting for 79.2 to $81.5 \%$ ), with phosphatidylglycerol (PG; 8.7 to $11.9 \%$ ) and cardiolipin (CL; 7.6 to 10.4\%) far less prolific (Supplementary Figure S4A). Elevated temperature did not dramatically impact on the relative levels of PE or PG being produced by any of the bacteria (Supplementary Figure S4A). On the other hand, bacteria lacking surA or SurA+ bacteria deficient in all four other periplasmic PPIases increased the proportion of CL and other minor phospholipids at elevated temperature (Supplementary Figure S4B). As anticipated from the total cellular FA profiles (see Supplementary Table S2 and Figure 7), the makeup of individual phospholipids at ambient temperature was dominated by UFA, but the relative levels of UFA and SFA equilibrated in bacteria grown at $37^{\circ} \mathrm{C}$ (Supplementary Figure S4C). In addition, the surA mutants routinely produced phospholipids composed of modestly higher levels of UFA irrespective of growth temperature (Supplementary Figure S4C). Thus, subtle alterations in fatty acid and lipid content occur in Y. pseudotuberculosis lacking surA, but generally not when lacking all four other periplasmic PPIases.

\section{Yersinia lacking surA are susceptible to diverse antimicrobials}

Given the obvious perturbations in the bacterial envelope of Yersinia surA mutants, we investigated if the envelope barrier function was compromised in these strains. All single mutants, the quadruple mutant and the quintuple mutant were subjected to growth in the presence of antibiotics (vancomycin, bacitracin), bile salts (a major component contained within YSA) and detergents (SDS, sodium deoxycholate). Quite expectedly, the two Y. pseudotuberculosis mutants lacking surA were more susceptible to these antimicrobials compared to any other strain (Supplementary Figure S5A and S5B). Envelope barrier function was restored to surA mutants by ectopic expression of a wild-type copy of surA. Not surprisingly, the surA mutants were modestly less able to maintain long-term viability during extended culturing (Supplementary Figure S5C). Remarkably, none of these conditions impeded growth of the SurA ${ }^{+}$quadruple mutant. Overall, this reflects a strict requirement of SurA for maintenance of envelope integrity in pathogenic $Y$. pseudotuberculosis.

\section{PPIases other than SurA are important for Yersinia survival during exposure to ROIs}

A confounding aspect of this study has been the lack of discernable phenotypes for the quadruple $\triangle p p i A \Delta p p i D \triangle f k p A \triangle f k l B$ mutant that still encodes an intact surA allele. Since it is unlikely that $Y$. pseudotuberculosis would retain proteins in the absence of any important function, we assessed the sensitivity of our mutants to hydrogen peroxide, the super-oxide generating compound menadione and acid stress. These are relevant stresses that must be counteracted by $Y$. pseudotuberculosis in order to survive during an intracellular lifecycle inside an infected host [26]. Decisively, exposure to hydrogen peroxide resulted in significant $(*, p<0.05)$ growth defects of the quadruple mutant, although to a lesser degree than $Y$. pseudotuberculosis lacking surA (Supplementary Figure S6). This result agrees with the recent finding that a Par10-negative E. coli strain was also more sensitive toward hydrogen peroxide than was the wild-type strain [27]. Significantly, the presence of hydrogen peroxide is the first in vitro growth condition in which the quadruple mutant displayed a reduced tolerance to stress. Interestingly however, this mutant did grow to the same level as parental bacteria in the presence of $200 \mu \mathrm{M}$ menadione, 
whereas surA mutants still displayed a significant growth defect (Supplementary Figure S6). These differential sensitivities of bacteria to hydrogen peroxide and menadione is not uncommon [28], possibly because the oxidative stress pathways for the superoxide and hydrogen peroxide sensing are independently regulated by SoxRS and OxyR respectively [29].

We also tested the sensitivity of these bacteria to increasingly acidic conditions. Despite $\mathrm{pH}$ 5.0 being bacteriostatic and $\mathrm{pH} 3.0$ being bacteriocidal for $Y$. pseudotuberculosis, we could not detect any differences between parental and mutant bacteria at either growth condition (data not shown). Thus unlike their protective effect against the action of ROIs, no periplasmic PPIase appeared to confer resistance to $Y$. pseudotuberculosis during growth in low $\mathrm{pH}$.

\section{PPIases and $Y$. pseudotuberculosis virulence}

The quadruple mutant ( $\triangle p p i A \Delta p p i D \Delta f k p A \Delta f k l B$ ) exhibited an in vitro growth defect in the presence of hydrogen peroxide - an antimicrobial compound commonly associated with activation of host immune cells during microbial infection. In light of this, we were keen to address if this mutant was attenuated during in vivo infections of female BALB/c mice. We scored attenuation on the basis of $\mathrm{ID}_{50}$ as determined by the extent of visible symptoms of infection, such as ruffled fur, weight loss, listlessness and diarrhoea. Mice infected with high doses $\left(10^{6}\right.$ and $\left.10^{5}\right)$ of parental $Y$. pseudotuberculosis were terminally infected within 4 and 8 days, respectively (Figure 8A). With these trends an $\mathrm{ID}_{50}$ of $2.0 \times 10^{4}$ could be calculated for the parental strain. On the other hand, mice infected with the single surA mutant, the quadruple PPIase mutant or the quintuple PPIase mutant were mostly symptom free (Figure 8A). This suggested that $\mathrm{ID}_{50}$ measurements for these mutant bacteria were in excess of $3.0 \times 10^{6}, 3.2 \times 10^{6}$ and $2.8 \times 10^{6}$, respectively; a 100-fold attenuation compared to the parent. Interestingly, we did observe a small degree of weight loss (Figure $8 \mathrm{~B}$ ) and ruffled fur (data not shown) in those mice infected with higher doses of the quadruple PPIase mutant. This was not evident in infections with surA mutant bacteria. We therefore conclude from these in vivo mouse infection studies that full $Y$. pseudotuberculosis pathogenicity does depend on a functioning collection of several periplasmic PPIases, and not solely on active SurA. Hence, one or more of the other periplasmic PPIases possess an important role in Y. pseudotuberculosis survival in a particular niche inside the infected host. We therefore interpret the two-log reduction in $\mathrm{ID}_{50}$ observed for $\mathrm{SurA}^{+}$and SurA $^{-}$bacteria to reflect SurA-dependent and SurA-independent modes of virulence attenuation.

\section{DISCUSSION}

In comparison to SurA [6], it has proven much more difficult to establish the physiological roles of the other periplasmic PPIases. FkpA is a PPIase with chaperone activity [23, 30] that might cooperate with SurA in the starvation stress response [31]. PpiD was originally described as a multicopy suppressor of surA [22] with recent reports also providing evidence of a periplasmic chaperone role $[32,33]$. On the other hand, FklB and PpiA functions still remain obscure. We used two types of functional assay to study a quadruple $\Delta p p i A \Delta p p i D \Delta f k p A \Delta f k l B$ deletion mutant still containing functional SurA, a single $\Delta$ surA mutant, and a quintuple $\Delta p p i A$ $\triangle p p i D \triangle f k p A \triangle f k l B \Delta s u r A$ deletion mutant lacking all five extracytoplasmic PPIases; those that broadly examined bacterial envelope integrity and those that scrutinize survival in the host. Only in the absence of SurA could we detect obvious defects in Yersinia envelope integrity. Yet, like the surA mutants, SurA $^{+}$bacteria lacking all other periplasmic PPIases were sensitive to conditions that mimicked the vacuolar environment inside an activated host immune cell (such as 
elevated hydrogen peroxide). Indeed, PPIases could have an important role during oxidative stress [27]. To this end, all three mutant bacteria were also highly attenuated in a mouseinfection model. These data imply that SurA cannot compensate for the collective loss of PpiA, PpiD, FkpA and FklB when Y. pseudotuberculosis enters a mammalian host, but it can during routine in vitro culturing. SurA is therefore generally required for bacterial survival during both in vitro and in vivo conditions, while all other periplasmic PPIases are required during growth in a particular ecological niche; most notably during mammalian infections. The mechanistic basis for these attenuating effects remain obscure; to define the in vivo roles for the PpiA, PpiD, FkpA and FklB PPIases during Y. pseudotuberculosis pathogenesis is a goal for the future. We anticipate that their roles in promoting pathogenicity are likely to be indirect. Perhaps in the absence of PpiA, PpiD, FkpA or FklB, one or more of their native substrates that are also important for Yersinia survival in vivo, fail to assemble in the outer membrane.

Having purified four of the five PPIases from Y. pseudotuberculosis, specific antibodies were generated to enable a definitive investigation into sub-cellular localization of SurA, PpiD, FkpA and FklB. While the localizations of SurA and FkpA in the periplasmic fraction and PpiD in the inner membrane are consistent with observations from $E$. coli $[22,23]$, we identified FklB to be predominately associated with the inner membrane, not the periplasm as previously reported for E. coli [5]. These two assays were performed differently, which may account for this discrepancy. On the other hand, FklB was recently seen to interact with inner membraneassociated thioredoxin [34]. Perhaps this is a transient interaction that could occasionally cause FklB to locate to the inner membrane. Further work is needed to resolve this inconsistency. Nonetheless, the extracytoplasmic compartmentalization of these PPIases in Yersinia ideally positions them for interactions with early protein folding intermediates in the periplasm.

SurA is the subject of intensive research (reviewed in [6]). It is critical for periplasmic quality control, particularly when the bacteria are faced with optimizing growth and survival in adverse environmental conditions. Although long regarded as a PPIase enzyme, evidence now supports a primary role of SurA as a chaperone assisting in the transport and assembly of a subset of outer membrane proteins $[35,36]$. In fact, the requirement for SurA PPIase-independent chaperone activity supersedes the need for its PPIase activity [35]. This could explain why we observed such low in vitro PPIase activity from SurA derived from Y. pseudotuberculosis, since the two Parvulin domains and the associated PPIase activity may only play a secondary role in SurA function. However, a role for the SurA Parvulin domains in protein folding in vivo during growth of the organism in some defined ecological niche should not be discounted. We intend to generate site-directed surA mutants to pinpoint whether the physiological defects in our existing full-length surA mutants are due to loss of SurA PPIase activity or chaperone activity.

Target substrates of SurA are thought to possess a W-X-W motif (where $\mathrm{W}$ is an aromatic amino acid) that is a characteristic of $\beta$-barrel proteins [37-39]. In our preliminary search for potential SurA targets in Yersinia, we identified a significant reduction of OmpA and the Pal lipoprotein in outer membrane fractions. OmpA, containing a singular W-X-W motif, constitutes a major component of the bacterial outer membrane and therefore possesses important pleiotropic functions [40]. OmpA levels are noticeably lessened in E. coli mutants lacking surA $[17,41]$ and SurA can interact with OmpA peptides [38]. However, it is unclear whether this interaction is a requirement for OmpA assembly in the outer membrane because ompA transcription is also diminished in surA mutants [42] and another periplasmic chaperone, Skp, is already implicated in OmpA assembly [43]. The outer membrane Pal lipoprotein also performs essential functions in the bacterial envelope [44]. As an integral component of the Tol-Pal 
system, it bridges the inner and outer membranes with the intervening peptidoglycan layer. Formation of these molecular bridges is dependent on the proton motive force and is necessary for cell division, solute transport across the inner membrane and the preservation of outer membrane integrity. Pal transport to the outer membrane is dependent on the Lol pathway [45]. Since Pal is not considered a true substrate of SurA [42], loss of surA may decrease Loldependent transport efficiency, perhaps as a result of alterations in membrane lipid content (discussed below) [46]. To define the true molecular targets of SurA in Y. pseudotuberculosis might well identify novel virulence factors essential for Yersinia survival during host infections.

To optimize growth in varied environments, bacteria actively regulate fatty acid composition to modulate lipid content and distribution in order to maintain membrane structure and function [47-49]. Clinically important bacteria, such as the Yersiniae, also alter lipid content as a means to evade the hostile host innate immune response [50, 51]. Significantly, alterations in fatty acid and lipid content specifically occurred in $Y$. pseudotuberculosis lacking surA. Presumably, this limits the adaptiveness of surA mutants to extracytoplasmic stress and the ability to instigate outer membrane repair, especially at elevated temperatures; a poorer survival outcome would result. SurA influence on fatty acid and lipid content could be direct or indirect, affecting de novo fatty acid or lipid biosynthesis, transport and assembly and/or modification of existing fatty acids or lipid structures. A simple explanation is that surA depletion indirectly stimulates an increased production of key fatty acids or lipids to compensate for the compromised envelope. This precedent exists given that chronic extracytoplasmic stress responsiveness affects LPS biogenesis [52] and deletion of surA constitutes a strong extracytoplasmic stress stimulant in $E$. coli [17]. It is also in balance with our observations that Yersinia surA mutants release significant amounts of LPS into the surrounding milieu. In view of this, it would be interesting to examined $\sigma^{\mathrm{E}}$ or Cpx pathway activity in Yersinia lacking surA. Knowing this may benefit our future understanding of the molecular connection between SurA and lipid biosynthesis/assembly in the Yersinia envelope.

\section{AUTHOR CONTRIBUTION}

Ikenna Obi, Roland Nordfelth and Matthew Francis designed, performed and analysed experiments. Ikenna Obi and Matthew Francis wrote the paper. All authors read and approved the final paper.

\section{ACKNOWLEDGEMENTS}

This work was performed within the virtual framework of the Umeå Centre for Microbial Research (UCMR), Linnaeus Program (LP). We express gratitude to Sidney Kushner (University of Georgia, Athens, CA) for the gift of pWKS30. We are also indebted to Vassillis Koronakis (University of Cambridge, Cambridge, UK), Teru Ogwa (Kumamoto University, Kumamoto, Japan) and Bernt Eric Uhlin (Umeå University, Umeå, Sweden) for their gifts of anti-TolC, anti$\mathrm{FtsH}$, and anti-HNS, respectively. In addition, we gratefully acknowledge the technical assistance of Lenore Johansson and Per Hörstedt at the Electron Microscopy Platform at KBC, Umeå University, for the provision of microscopy images. Thanks are also extended to Mark Dopson (Umeå University) for his assistance in performing MALDI-TOF mass spectrometric analysis and Sun Nyunt Wai (Umeå University) for her discussions concerning outer membrane 
turnover and leakiness. Finally, Hans Wolf-Watz (Umeå University) is acknowledged for his valuable insights into the $Y$. pseudotuberculosis virulence study.

\section{FUNDING}

Performed within the virtual framework of the UCMR- LP, this work was supported by the Swedish Research Council (2006-3869 and 2009-3660), the Carl Tryggers Foundation for Scientific Research (06:141) and the Foundation for Medical Research at Umeå University. IRO is supported by a UCMR-LP post-doctoral fellowship.

\section{REFERENCES}

1 Golbik, R., Yu, C., Weyher-Stingl, E., Huber, R., Moroder, L., Budisa, N. and SchieneFischer, C. (2005) Peptidyl prolyl cis/trans-isomerases: comparative reactivities of cyclophilins, FK506-binding proteins, and parvulins with fluorinated oligopeptide and protein substrates. Biochemistry 44, 16026-16034

2 Fanghanel, J. and Fischer, G. (2004) Insights into the catalytic mechanism of peptidyl prolyl cis/trans isomerases. Front. Biosci. 9, 3453-3478

3 Kolaj, O., Spada, S., Robin, S. and Wall, J. G. (2009) Use of folding modulators to improve heterologous protein production in Escherichia coli. Microb. Cell Fact. 8, 9

4 Leverrier, P., Vertommen, D. and Collet, J. F. Contribution of proteomics toward solving the fascinating mysteries of the biogenesis of the envelope of Escherichia coli. Proteomics 10, 771-784

5 Rahfeld, J. U., Rucknagel, K. P., Stoller, G., Horne, S. M., Schierhorn, A., Young, K. D. and Fischer, G. (1996) Isolation and amino acid sequence of a new 22-kDa FKBP-like peptidylprolyl cis/trans-isomerase of Escherichia coli. Similarity to Mip-like proteins of pathogenic bacteria. J. Biol. Chem. 271, 22130-22138

6 Behrens-Kneip, S. (2010) The role of SurA factor in outer membrane protein transport and virulence. Int. J. Med. Microbiol. 300, 421-428

7 Naktin, J. and Beavis, K. G. (1999) Yersinia enterocolitica and Yersinia pseudotuberculosis. Clin Lab Med. 19, 523-536, vi

8 Wren, B. W. (2003) The yersiniae--a model genus to study the rapid evolution of bacterial pathogens. Nat. Rev. Microbiol. 1, 55-64

9 Blattner, F. R., Plunkett, G., 3rd, Bloch, C. A., Perna, N. T., Burland, V., Riley, M., ColladoVides, J., Glasner, J. D., Rode, C. K., Mayhew, G. F., Gregor, J., Davis, N. W., Kirkpatrick, H. A., Goeden, M. A., Rose, D. J., Mau, B. and Shao, Y. (1997) The complete genome sequence of Escherichia coli K-12. Science 277, 1453-1474

10 Francis, M. S. and Wolf-Watz, H. (1998) YopD of Yersinia pseudotuberculosis is translocated into the cytosol of HeLa epithelial cells: evidence of a structural domain necessary for translocation. Mol. Microbiol. 29, 799-813

11 Kofron, J. L., Kuzmic, P., Kishore, V., Colon-Bonilla, E. and Rich, D. H. (1991) Determination of kinetic constants for peptidyl prolyl cis-trans isomerases by an improved spectrophotometric assay. Biochemistry 30, 6127-6134

12 Potrykus, J., Jonna, V. R. and Dopson, M. (2011) Iron homeostasis and responses to iron limitation in extreme acidophiles from the Ferroplasma genus. Proteomics 11, 52-63 
13 Wai, S. N., Lindmark, B., Soderblom, T., Takade, A., Westermark, M., Oscarsson, J., Jass, J., Richter-Dahlfors, A., Mizunoe, Y. and Uhlin, B. E. (2003) Vesicle-mediated export and assembly of pore-forming oligomers of the enterobacterial ClyA cytotoxin. Cell 115, 25-35

14 Folch, J., Lees, M. and Sloane Stanley, G. H. (1957) A simple method for the isolation and purification of total lipides from animal tissues. J. Biol. Chem. 226, 497-509

15 Reed, L. J. and Muench, H. (1938) A simple method for estimating fifty percent endpoints. Am. J. Hyg. 27, 493-497

16 Weininger, U., Jakob, R. P., Kovermann, M., Balbach, J. and Schmid, F. X. (2010) The prolyl isomerase domain of PpiD from Escherichia coli shows a parvulin fold but is devoid of catalytic activity. Protein Sci. 19, 6-18

17 Rouviere, P. E. and Gross, C. A. (1996) SurA, a periplasmic protein with peptidyl-prolyl isomerase activity, participates in the assembly of outer membrane porins. Genes Dev. 10, 3170-3182

18 Missiakas, D., Betton, J. M. and Raina, S. (1996) New components of protein folding in extracytoplasmic compartments of Escherichia coli SurA, FkpA and Skp/OmpH. Mol. Microbiol. 21, 871-884

19 Furutani, M., Iida, T., Yamano, S., Kamino, K. and Maruyama, T. (1998) Biochemical and genetic characterization of an FK506-sensitive peptidyl prolyl cis-trans isomerase from a thermophilic archaeon, Methanococcus thermolithotrophicus. J. Bacteriol. 180, 388-394

20 Harrison, R. K. and Stein, R. L. (1990) Substrate specificities of the peptidyl prolyl cis-trans isomerase activities of cyclophilin and FK-506 binding protein: evidence for the existence of a family of distinct enzymes. Biochemistry 29, 3813-3816

21 Van Duyne, G. D., Standaert, R. F., Karplus, P. A., Schreiber, S. L. and Clardy, J. (1991) Atomic structure of FKBP-FK506, an immunophilin-immunosuppressant complex. Science 252, 839-842

22 Dartigalongue, C. and Raina, S. (1998) A new heat-shock gene, ppiD, encodes a peptidylprolyl isomerase required for folding of outer membrane proteins in Escherichia coli. EMBO J. 17, 3968-3980

23 Arie, J. P., Sassoon, N. and Betton, J. M. (2001) Chaperone function of FkpA, a heat shock prolyl isomerase, in the periplasm of Escherichia coli. Mol. Microbiol. 39, 199-210

24 Krasikova, I. N., Khotimchenko, S. V., Solov'eva, T. F. and Ovodov, Y. S. (1995) Mutual influence of plasmid profile and growth temperature on the lipid composition of Yersinia pseudotuberculosis bacteria. Biochim. Biophys. Acta 1257, 118-124

25 Bakholdina, S. I., Sanina, N. M., Krasikova, I. N., Popova, O. B. and Solov'eva, T. F. (2004) The impact of abiotic factors (temperature and glucose) on physicochemical properties of lipids from Yersinia pseudotuberculosis. Biochimie 86, 875-881

26 Pujol, C. and Bliska, J. B. (2005) Turning Yersinia pathogenesis outside in: subversion of macrophage function by intracellular yersiniae. Clin. Immunol. 114, 216-226

27 Malesevic, M., Poehlmann, A., Hernandez Alvarez, B., Diessner, A., Trager, M., Rahfeld, J. U., Jahreis, G., Liebscher, S., Bordusa, F., Fischer, G. and Lucke, C. (2010) The protein-free IANUS peptide array uncovers interaction sites between Escherichia coli parvulin 10 and alkyl hydroperoxide reductase. Biochemistry 49, 8626-8635

28 Palyada, K., Sun, Y. Q., Flint, A., Butcher, J., Naikare, H. and Stintzi, A. (2009) Characterization of the oxidative stress stimulon and PerR regulon of Campylobacter jejuni. BMC Genomics. 10, 481 
29 Imlay, J. A. (2008) Cellular defenses against superoxide and hydrogen peroxide. Annu. Rev. Biochem. 77, 755-776

30 Ramm, K. and Pluckthun, A. (2001) High enzymatic activity and chaperone function are mechanistically related features of the dimeric E. coli peptidyl-prolyl-isomerase FkpA. J. Mol. Biol. 310, 485-498

31 Kenyon, W. J., Humphreys, S., Roberts, M. and Spector, M. P. (2010) Periplasmic peptidylprolyl isomerases SurA and FkpA play an important role in the starvation-stress response (SSR) of Salmonella enterica serovar Typhimurium. Antonie Van Leeuwenhoek 98, 51-63

32 Antonoaea, R., Furst, M., Nishiyama, K. and Muller, M. (2008) The periplasmic chaperone PpiD interacts with secretory proteins exiting from the SecYEG translocon. Biochemistry 47, 5649-5656

33 Matern, Y., Barion, B. and Behrens-Kneip, S. (2010) PpiD is a player in the network of periplasmic chaperones in Escherichia coli. BMC Microbiol. 10, 251

34 Kumar, J. K., Tabor, S. and Richardson, C. C. (2004) Proteomic analysis of thioredoxintargeted proteins in Escherichia coli. Proc. Natl. Acad. Sci. U S A. 101, 3759-3764

35 Behrens, S., Maier, R., de Cock, H., Schmid, F. X. and Gross, C. A. (2001) The SurA periplasmic PPIase lacking its parvulin domains functions in vivo and has chaperone activity. EMBO J. 20, 285-294

36 Sklar, J. G., Wu, T., Kahne, D. and Silhavy, T. J. (2007) Defining the roles of the periplasmic chaperones SurA, Skp, and DegP in Escherichia coli. Genes Dev. 21, 24732484

37 Bitto, E. and McKay, D. B. (2003) The periplasmic molecular chaperone protein SurA binds a peptide motif that is characteristic of integral outer membrane proteins. J. Biol. Chem. 278, 49316-49322

38 Hennecke, G., Nolte, J., Volkmer-Engert, R., Schneider-Mergener, J. and Behrens, S. (2005) The periplasmic chaperone SurA exploits two features characteristic of integral outer membrane proteins for selective substrate recognition. J. Biol. Chem. 280, 23540-23548

39 Webb, H. M., Ruddock, L. W., Marchant, R. J., Jonas, K. and Klappa, P. (2001) Interaction of the periplasmic peptidylprolyl cis-trans isomerase SurA with model peptides. The Nterminal region of SurA is essential and sufficient for peptide binding. J. Biol. Chem. 276, 45622-45627

40 Smith, S. G., Mahon, V., Lambert, M. A. and Fagan, R. P. (2007) A molecular Swiss army knife: OmpA structure, function and expression. FEMS Microbiol. Lett. 273, 1-11

41 Justice, S. S., Hunstad, D. A., Harper, J. R., Duguay, A. R., Pinkner, J. S., Bann, J., Frieden, C., Silhavy, T. J. and Hultgren, S. J. (2005) Periplasmic peptidyl prolyl cis-trans isomerases are not essential for viability, but SurA is required for pilus biogenesis in Escherichia coli. J. Bacteriol. 187, 7680-7686

42 Vertommen, D., Ruiz, N., Leverrier, P., Silhavy, T. J. and Collet, J. F. (2009) Characterization of the role of the Escherichia coli periplasmic chaperone SurA using differential proteomics. Proteomics 9, 2432-2443

43 Schafer, U., Beck, K. and Muller, M. (1999) Skp, a molecular chaperone of gram-negative bacteria, is required for the formation of soluble periplasmic intermediates of outer membrane proteins. J. Biol. Chem. 274, 24567-24574

44 Godlewska, R., Wisniewska, K., Pietras, Z. and Jagusztyn-Krynicka, E. K. (2009) Peptidoglycan-associated lipoprotein (Pal) of Gram-negative bacteria: function, structure, 
role in pathogenesis and potential application in immunoprophylaxis. FEMS Microbiol. Lett. 298, $1-11$

45 Masuda, K., Matsuyama, S. and Tokuda, H. (2002) Elucidation of the function of lipoprotein-sorting signals that determine membrane localization. Proc. Natl. Acad. Sci. U S A. 99, 7390-7395

46 Miyamoto, S. and Tokuda, H. (2007) Diverse effects of phospholipids on lipoprotein sorting and ATP hydrolysis by the ABC transporter LolCDE complex. Biochim. Biophys. Acta. 1768, 1848-1854

47 Mansilla, M. C., Cybulski, L. E., Albanesi, D. and de Mendoza, D. (2004) Control of membrane lipid fluidity by molecular thermosensors. J. Bacteriol. 186, 6681-6688

48 Mileykovskaya, E. and Dowhan, W. (2005) Role of membrane lipids in bacterial divisionsite selection. Curr. Opin. Microbiol. 8, 135-142

49 van Dalen, A. and de Kruijff, B. (2004) The role of lipids in membrane insertion and translocation of bacterial proteins. Biochim. Biophys. Acta 1694, 97-109

50 Peschel, A. (2002) How do bacteria resist human antimicrobial peptides? Trends Microbiol. 10, 179-186

51 Trent, M. S., Stead, C. M., Tran, A. X. and Hankins, J. V. (2006) Diversity of endotoxin and its impact on pathogenesis. J. Endotoxin Res. 12, 205-223

52 Vines, E. D., Marolda, C. L., Balachandran, A. and Valvano, M. A. (2005) Defective Oantigen polymerization in tolA and pal mutants of Escherichia coli in response to extracytoplasmic stress. J. Bacteriol. 187, 3359-3368

53 Simon, R., Priefer, U. and Pühler, A. (1983) A broad host range mobilisation system for in vivo genetic engineering: transposon mutagenesis in Gram negative bacteria. Biotechnology $1,787-796$ 


\section{FIGURE LEGENDS}

\section{Figure 1 Periplasmic PPIases of Y. pseudotuberculosis YPIII}

Schematic representation of the genetic organization of gene loci of $Y$. pseudotuberculosis periplasmic PPIases (A). surA (NCBI annotation YPK_3571), ppiA (YPK_0242) and fkpA (YPK_0270) are all coded on the sense strand at genome positions $3935985-3937289,284007$ -284576 and $309956-310756$, while ppiD (YPK 3230) and fklB (YPK 3778) are coded on the complementary strand at genome positions 3531083 - 3532969 and 4168658 - 4169278 , respectively. Symbols denote genes encoding helix-hairpin-helix repeat-containing competence protein ComEA $(\S)$, transcriptional regulator subunit beta $(*)$, glycoside hydrolase family protein $(* *)$, putative NPT hydrolase $(* * *)$, SlyX $(+)$, YheO domain-containing protein $(++)$, ironsulfur cluster repair di-iron protein (\#) and opacity-associated protein A (\#\#). Predicted gene names are given in parenthesis or denoted by a symbol to reflect function. Amino acid sequence identity of periplasmic PPIases from Y. enterocolitica 8081, Y. pestis CO92, E. coli K12 MG1655 and Y. pseudotuberculosis YPIII (B). Amino acid sequences were aligned using the BLAST algorithm. NCBI annotation is provided in square brackets and the numbers in round brackets represents the length of each protein in amino acids. Domain organization of periplasmic PPIases from Y. pseudotuberculosis (C). The predicted molecular weight for each protein is provided in parentheses.

\section{Figure 2 Purification of $Y$. pseudotuberculosis periplasmic PPIases}

The purified recombinant proteins over-produced in E. coli BL21 were boiled for 5 min in SDS sample buffer and separated on $12 \%$ SDS polyacrylamide gels. Proteins were stained with Coomassie Blue. Approximate molecular weights of the individual protein bands in the PageRuler Prestained Protein ladder (Fermentas Life Sciences) are provided to the left of the panel. Adjacent lanes are purified recombinant SurA, PpiD, FkpA and FklB, respectively.

\section{Figure 3 PPIase activity of recombinant SurA, PpiD, FkpA and FklB}

Progress curves for the cis/trans isomerization of the chromogenic peptide Suc-Ala-Leu-ProPhe-pNa (A). $\alpha$-chymotrypsin-mediated hydrolysis of Suc-Ala-Leu-Pro-Phe-pNa was measured in the absence or presence of $0.1 \mu \mathrm{M}$ recombinant SurA, PpiD, FkpA, FklB or CpxR (protein negative control) at $10{ }^{\circ} \mathrm{C}$ for 3 minutes. PPIase activity of SurA, FkpA and FklB is concentration dependent (B). Various concentrations of the recombinant proteins were assayed for PPIase activity and the rate constants were calculated by fitting the absorbance data to a firstorder exponential rise function. All data-points were an average of three independent measurements ( \pm standard deviation) and were highly reproducible.

\section{Figure 4 Inhibition of PPIase activity with immunosuppressive drugs}

Inhibition assay was measured with $0.1 \mu \mathrm{M} \operatorname{SurA}(\mathbf{A}), \operatorname{FkpA}(\mathbf{B})$ or FklB (C) in 50mM Tris-HCl, $\mathrm{pH} 8$ at $10{ }^{\circ} \mathrm{C}$ using Suc-Ala-Leu-Pro-Phe-pNa as substrate in the presence of different concentrations of the immunosuppressants CsA, FK506 and rampamycin prepared in ethanol/water $(1: 1, \mathrm{v} / \mathrm{v})$. Remaining activity was calculated using the rate constants in the presence of the inhibitors. Note that the final concentration of ethanol in the assay mixture was 1 $\%$, but this had negligible effect on PPIase activity as determined by control assays in the presence of ethanol alone (data not shown). All data-points were an average of three independent measurements ( \pm standard deviation) and were highly reproducible. 
Figure 5 Sub-cellular localization of SurA, PpiD, FkpA and FklB in Y. pseudotuberculosis An overnight culture of $Y$. pseudotuberculosis was sub-cultured in fresh LB broth. After $2 \mathrm{~h}$, the bacteria were harvested and whole cell-lysate was separated into outer membrane, periplasmic, inner membrane and cytoplasmic fractions. TolC, MBP, FtsH and H-NS were used as outer membrane, periplasmic, inner membrane and cytoplasmic markers to control the purity of the fractionation, respectively. Each cellular fraction was then probed with anti-SurA, anti-PpiD, anti-FkpA and anti-FklB antibodies.

Figure 6 Transmission electron microscopy of PPIase mutants of Y. pseudotuberculosis Cultures were grown on LB agar at $26{ }^{\circ} \mathrm{C}$ prior to the TEM analysis of the parental strain (A), surA single mutant $(\Delta s u r A)(\mathbf{B})$, surA single mutant $(\Delta s u r A)$ trans-complemented with surA $(\mathbf{C})$, quadruple mutant $(\Delta p p i A \Delta p p i D \Delta f k p A \Delta f k l B)(\mathbf{D})$, quintuple mutant $(\Delta p p i A \Delta p p i D \Delta f k p A \Delta f k l B$ $\Delta$ surA) (E), quintuple mutant ( $\triangle$ ppiA $\Delta p p i D \Delta f k p A \Delta f k l B \Delta s u r A)$ trans-complemented with surA $(F)$. Arrows indicate the abundance of material released into the extracellular milieu by Yersinia mutants lacking surA. Scale bar $=0.5 \mu \mathrm{m}$.

Figure 7 Comparative analysis of the fatty acid levels in isogenic strains of $Y$. pseudotuberculosis lacking periplasmic PPIases

Relative fatty acid levels were calculated from the free $\mathrm{mg}$ fatty acid/100 $\mathrm{g}$ total lipid samples (see Supplementary Table S2) extracted from exponentially grown parent, surA single mutant $(\Delta s u r A)$, quadruple mutant $(\Delta p p i A \Delta p p i D \Delta f k p A \Delta f k l B)$ and quintuple mutant $(\Delta p p i A \Delta p p i D$ $\Delta f k p A \Delta f k l B \Delta s u r A)$ bacteria. Raw data is represented as the percentage (\%) of saturated (SFA), unsaturated (UFA) and cyclic (CFA) fatty acids from bacteria grown at $26^{\circ} \mathrm{C}$ and $37^{\circ} \mathrm{C}$ (A) and the ratio of SFA, UFA and CFA content at $37^{\circ} \mathrm{C}$ compared to $26^{\circ} \mathrm{C}(\mathbf{B})$. Shown is the average of three highly reproducible measurements ( \pm standard deviation).

\section{Figure 8 PPIases are required for virulence in mice}

Dilutions of $Y$. pseudotuberculosis parent and mutant bacteria were prepared from washed pellets that were serially diluted to $10^{7}, 10^{6}$ and $10^{5} \mathrm{CFU} / \mathrm{ml}$ in PBS. Mice were then injected intraperitoneally with $0.1 \mathrm{ml}$ to give final inocula of approximately $10^{6}, 10^{5}$ and $10^{4}$ bacteria per mouse (5 mice for each strain and dilution). Mice were observed for 14 days post-injection for survival (A) and alterations in their body weight (B). In A, only mice infected with dilutions of parental bacteria show any visible signs of infection. Hence much of the data reflects healthy symptom-free mice that are concealed by the bold solid grey line stylised with a filled square symbol. 
Table 1 Bacterial strains and plasmids used in this study

\begin{tabular}{|c|c|c|}
\hline Strain or plasmid & Relevant genotype or phenotype & $\begin{array}{l}\text { Source or } \\
\text { reference }\end{array}$ \\
\hline \multicolumn{3}{|l|}{ Strain } \\
\hline \multicolumn{3}{|l|}{ E. coli } \\
\hline DH5 & $\begin{array}{l}\mathrm{F}^{-} \text {recA1, endA1, hsdR } 17 \text {, supE44, thi-1, gyrA96, } \\
\text { relA1 }\end{array}$ & Vicky Shingler \\
\hline BL21 & $\mathrm{F}^{-}$dcm omp T hsdS $\left(\mathrm{r}_{\mathrm{B}^{-}}-\mathrm{m}_{\mathrm{B}^{-}}\right)$gal $\left(\text {malB }^{+}\right)_{\mathrm{K}-12}\left(\lambda^{\mathrm{S}}\right)$ & \\
\hline S17-1 $1 \lambda$ pir & $\begin{array}{l}\text { recA, thi, pro, hsdR } M^{+}, \mathrm{Sm}^{\mathrm{R}},<\mathrm{RP} 4-2-\mathrm{Tc}-\mathrm{Mu}-\mathrm{Ku}- \\
\operatorname{Tn} 7>\mathrm{Tp}^{\mathrm{R}}\end{array}$ & {$[53]$} \\
\hline \multicolumn{3}{|c|}{ Y. pseudotuberculosis } \\
\hline YPIII/pIB102 & yadA::Tn5 (parent), inactive PhoP, $\mathrm{Km}^{\mathrm{R}}$ & Hans Wolf-Watz \\
\hline YPIII20/pIB102 & ppiA in-frame deletion of codons 49 to $177, \mathrm{Km}^{\mathrm{R}}$ & This study \\
\hline YPIII21/pIB102 & surA in-frame deletion of codons 26 to $411, \mathrm{Km}^{\mathrm{R}}$ & This study \\
\hline YPIII22/pIB102 & fklB in-frame deletion of codons 16 to $188, \mathrm{Km}^{\mathrm{R}}$ & This study \\
\hline YPIII38/pIB102 & fkpA in-frame deletion of codons 20 to $247, \mathrm{Km}^{\mathrm{R}}$ & This study \\
\hline YPIII53/pIB102 & ppiD in-frame deletion of codons 14 to $604, \mathrm{Km}^{\mathrm{R}}$ & This study \\
\hline YPIII73/pIB102 & ppiA, ppiD, fklB, fkpA in-frame deletion, $\mathrm{Km}^{\mathrm{R}}$ & This study \\
\hline YPIII80/pIB102 & surA, ppiA, ppiD, fklB, fkpA in-frame deletion, $\mathrm{Km}^{\mathrm{R}}$ & This study \\
\hline \multicolumn{3}{|c|}{ 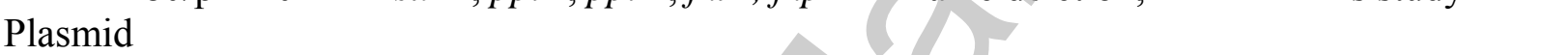 } \\
\hline pDM4 & Suicide mutagenesis plasmid carrying sacBR, $\mathrm{Cm}^{\mathrm{R}}$ & Debra Milton \\
\hline pMF658 & $\begin{array}{l}\sim 465 \text { bp XhoI/XbaI PCR fragment encoding the full- } \\
\text { length surA deletion allele in } \mathrm{pDM} 4, \mathrm{Cm}^{\mathrm{R}}\end{array}$ & This study \\
\hline pMF653 & $\begin{array}{l}\sim 435 \text { bp XbaI/XhoI PCR fragment encoding the full- } \\
\text { length ppiA deletion allele in pDM } 4, \mathrm{Cm}^{\mathrm{R}}\end{array}$ & This study \\
\hline pMF688 & $\begin{array}{l}\sim 45 \mathrm{bp} \text { XhoI/XbaI PCR fragment encoding the full- } \\
\text { length ppiD deletion allele in } \mathrm{pDM} 4, \mathrm{Cm}^{\mathrm{R}}\end{array}$ & This study \\
\hline pMF679 & $\begin{array}{l}\sim 505 \mathrm{bp} X \mathrm{X} O \mathrm{I} / \mathrm{XbaI} \mathrm{PCR} \text { fragment encoding the full- } \\
\text { length fkpA deletion allele in } \mathrm{pDM} 4, \mathrm{Cm}^{\mathrm{R}}\end{array}$ & This study \\
\hline pMF655 & $\begin{array}{l}\sim 530 \text { bp XhoI/XbaI PCR fragment encoding the full- } \\
\text { length fklB deletion allele in } \mathrm{pDM} 4, \mathrm{Cm}^{\mathrm{R}}\end{array}$ & This study \\
\hline pET30a $(+)$ & Expression vector, $\mathrm{Km}^{\mathrm{R}}$ & Novagen \\
\hline pIR001 & $\begin{array}{l}\sim 621 \mathrm{bp} \text { NCOI/HindIII PCR fragment of } f k l B \text { in } \\
\mathrm{pET} 30 \mathrm{a}(+), \mathrm{Km}^{\mathrm{R}}\end{array}$ & This study \\
\hline pIR002 & $\begin{array}{l}\sim 801 \text { bp NcoI/HindIII PCR fragment of } f k p A \text { in } \\
\text { pET30a }(+), \mathrm{Km}^{\mathrm{R}}\end{array}$ & This study \\
\hline pIR003 & $\begin{array}{l}\sim 1305 \mathrm{bp} \mathrm{NCOI/HindIII} \mathrm{PCR} \mathrm{fragment} \mathrm{of} \mathrm{surA} \mathrm{in} \\
\text { pET30a }(+), \mathrm{Km}^{\mathrm{R}}\end{array}$ & This study \\
\hline pIR004 & $\begin{array}{l}\sim 570 \mathrm{bp} \mathrm{NCOI/HindIII} \mathrm{PCR} \mathrm{fragment} \mathrm{of} \mathrm{ppiA} \mathrm{in} \\
\text { pET30a }(+), \mathrm{Km}^{\mathrm{R}}\end{array}$ & This study \\
\hline $\mathrm{p}$ & $\begin{array}{l}\sim 1887 \text { bp NCoI/BamHI PCR fragment of ppiD in } \\
\text { pET30a }(+), \mathrm{Km}^{\mathrm{R}}\end{array}$ & This study \\
\hline pWKS30 & Low-copy number cloning plasmid, $\mathrm{Cb}^{\mathrm{R}}$ & Sidney Kushner \\
\hline pIR005 & $\begin{array}{l}\sim 2200 \mathrm{bp} \mathrm{XbaI} / \mathrm{XhoI} \text { PCR fragment of surA with its } \\
\text { native promoter in } \mathrm{pWKS} 30, \mathrm{Cb}^{\mathrm{R}}\end{array}$ & This study \\
\hline
\end{tabular}


Figure 1: Obi et al., 2011

A
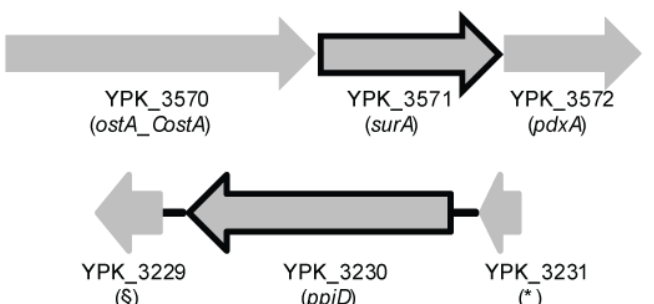

(§) (ppiD)
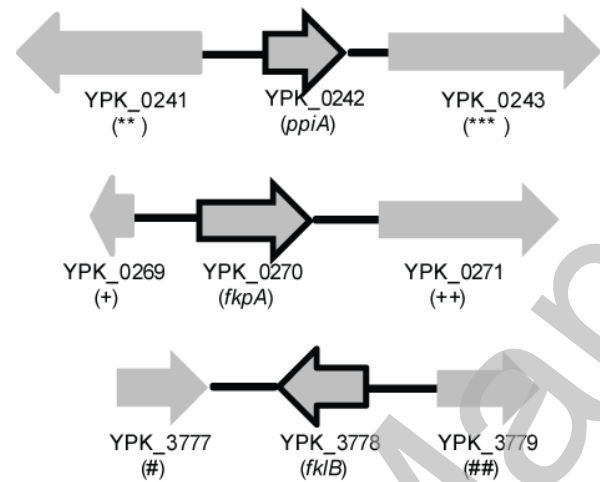

B

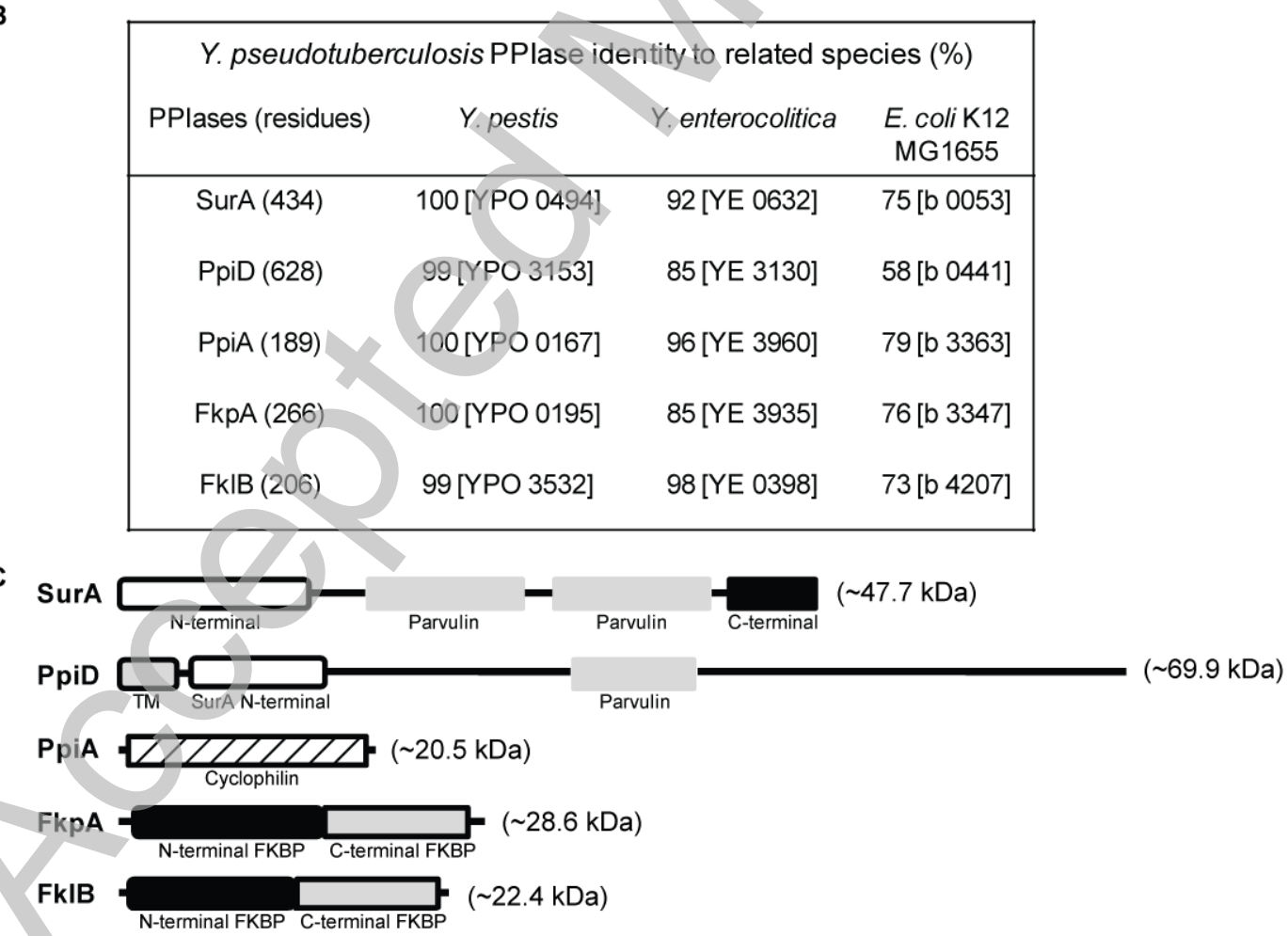

Licenced copy. Copying is not permitted, except with prior permission and as allowed by law.

(c) 2011 The Authors Journal compilation (c) 2011 Portland Press Limited 
Figure 2: Obi et al., 2011

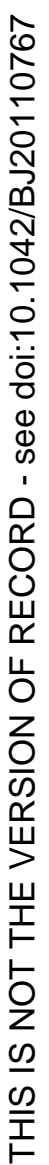


Figure 3: Obi et al., 2011

A

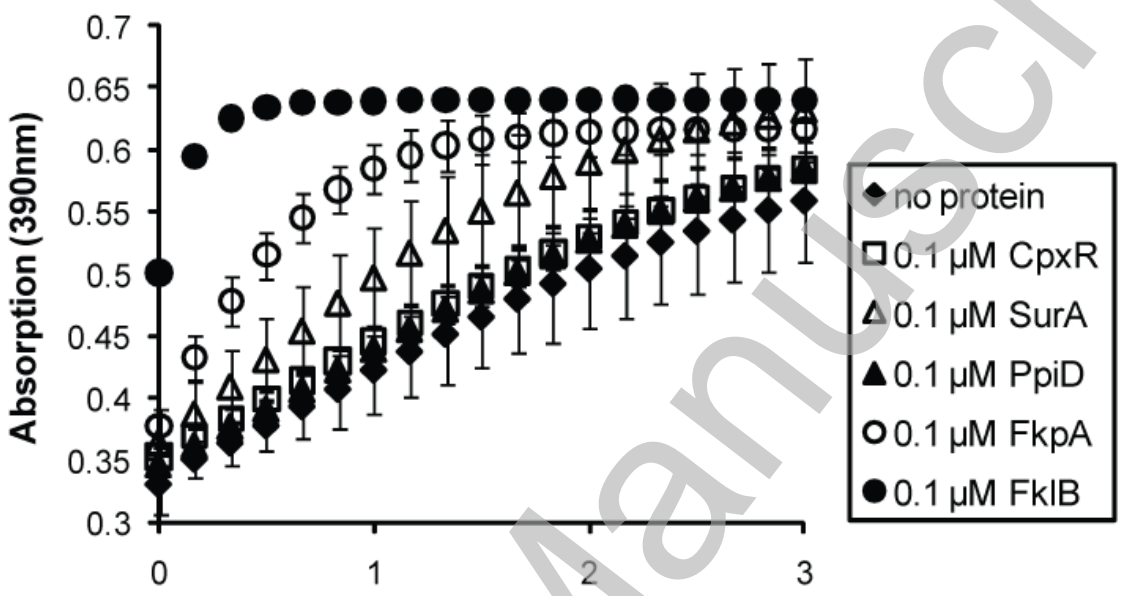

Time (minutes)

B

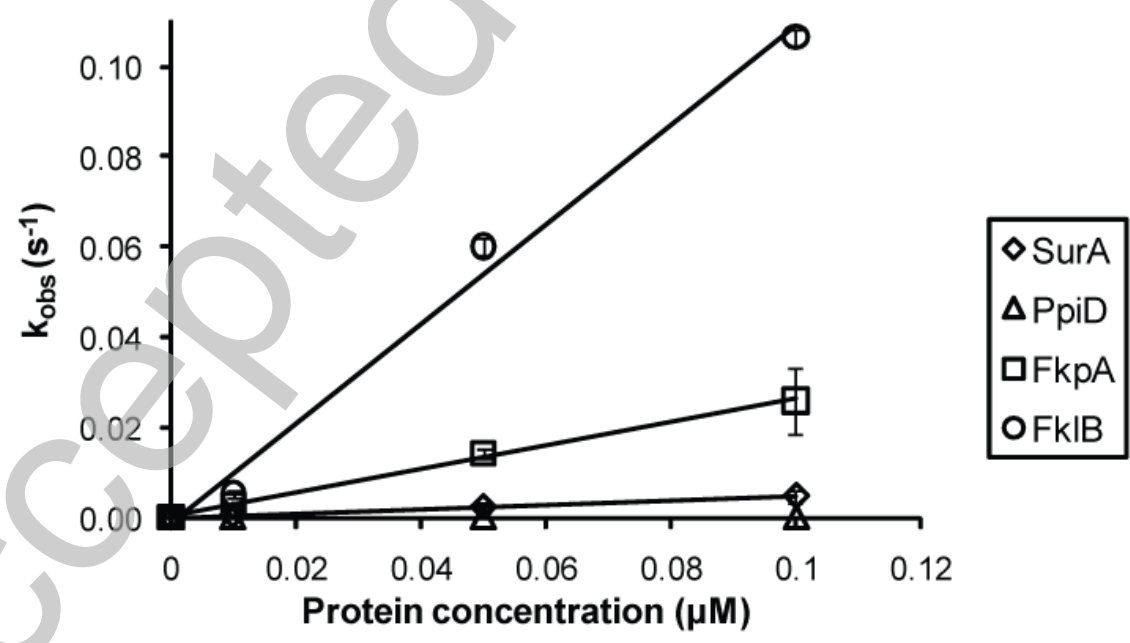


Figure 4: Obi et al., 2011

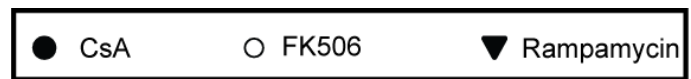

A

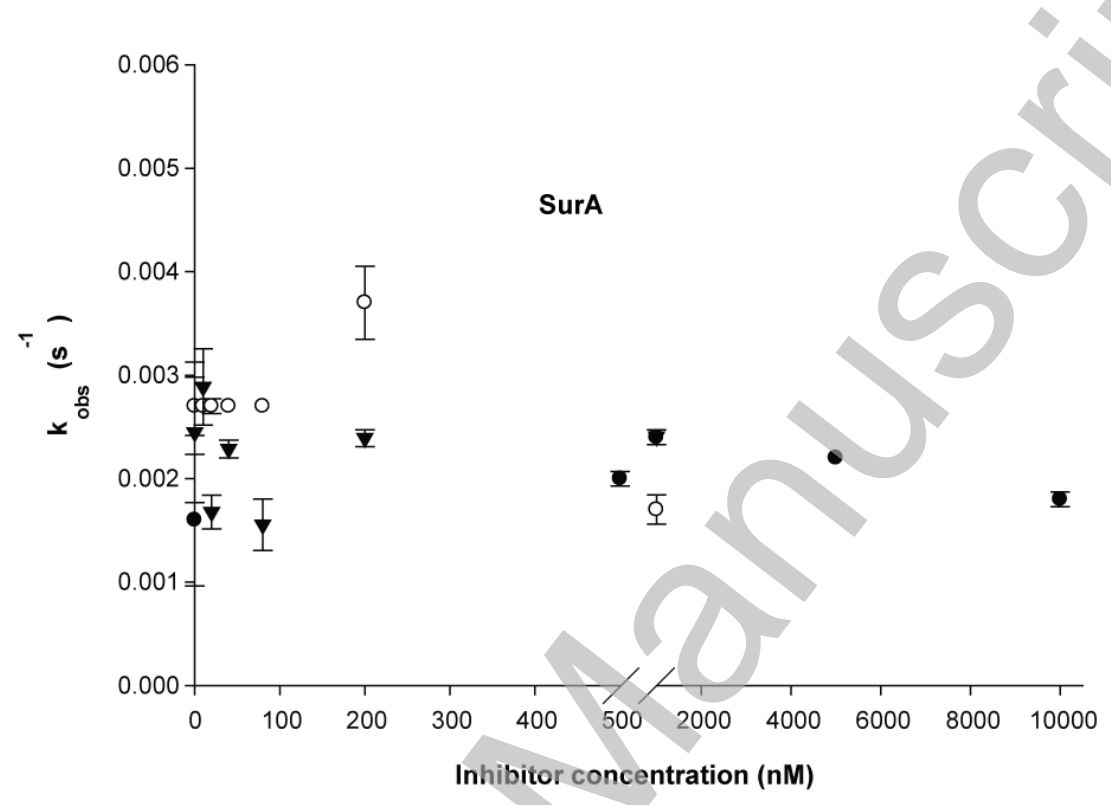

B

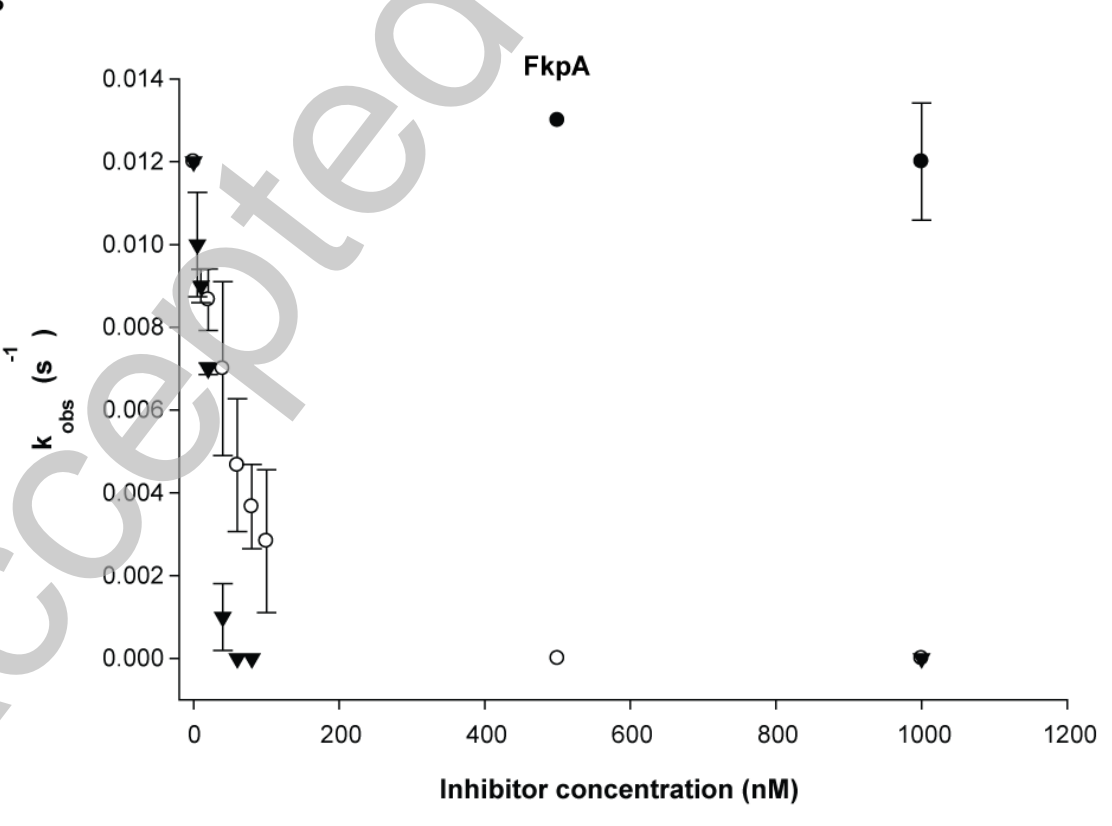


C

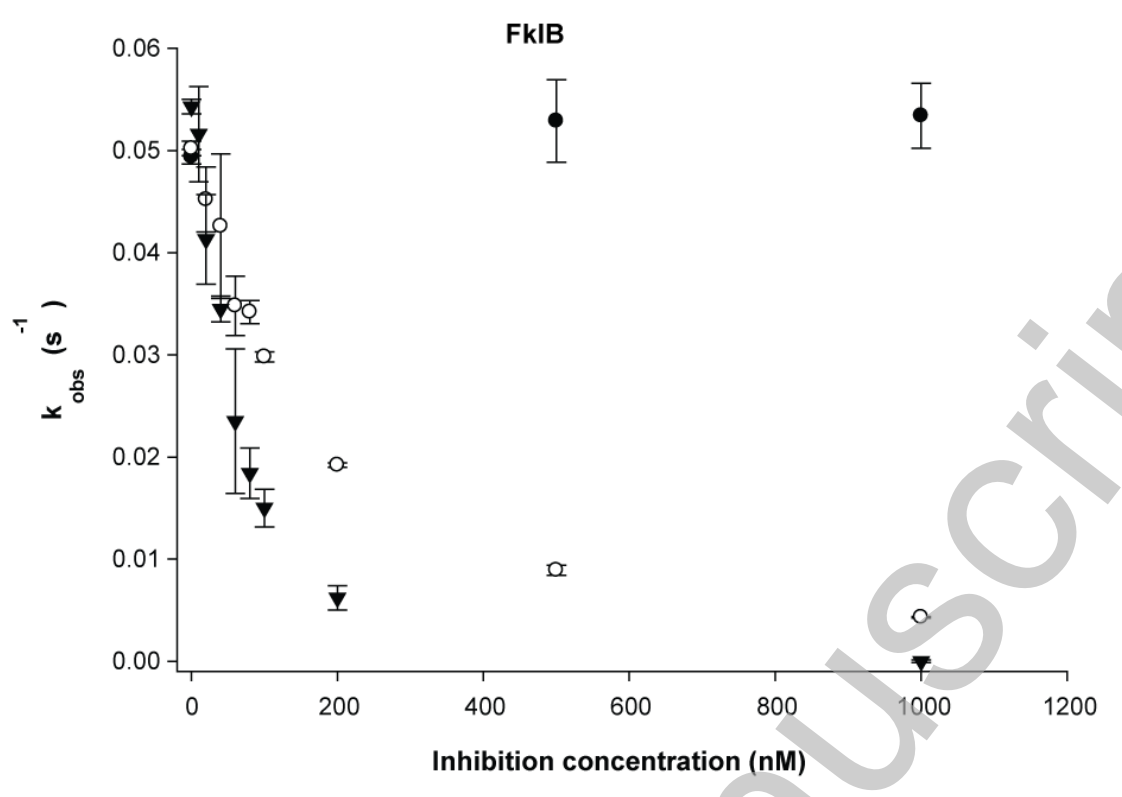


Figure 5: Obi et al., 2011

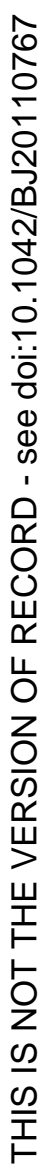

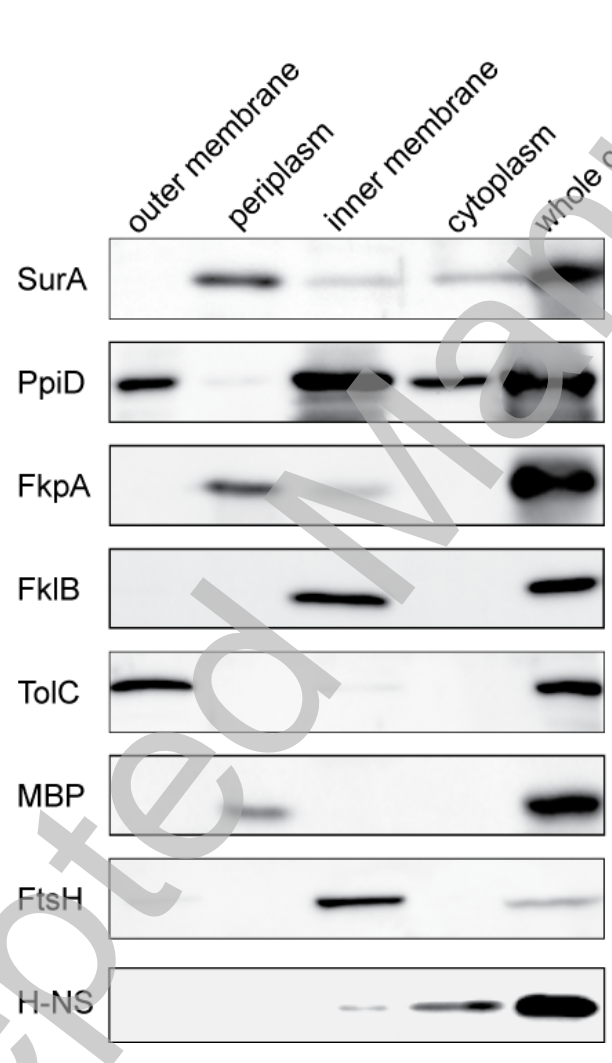


B Biochemical Journal Immediate Publication. Published on 04 Jul 2011 as manuscript BJ20110767

Figure 6: Obi et al., 2011
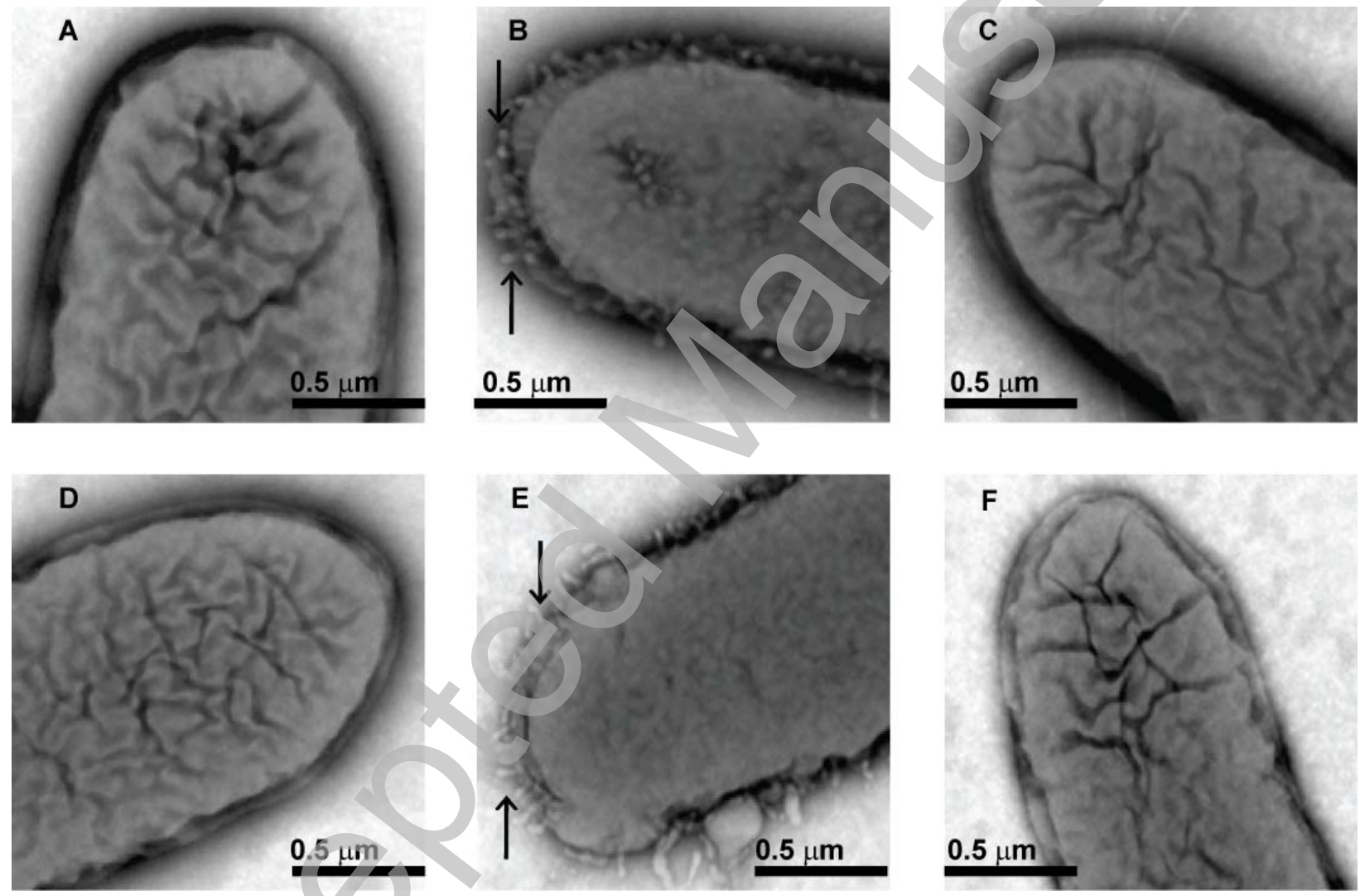
Figure 7: Obi et al., 2011

A

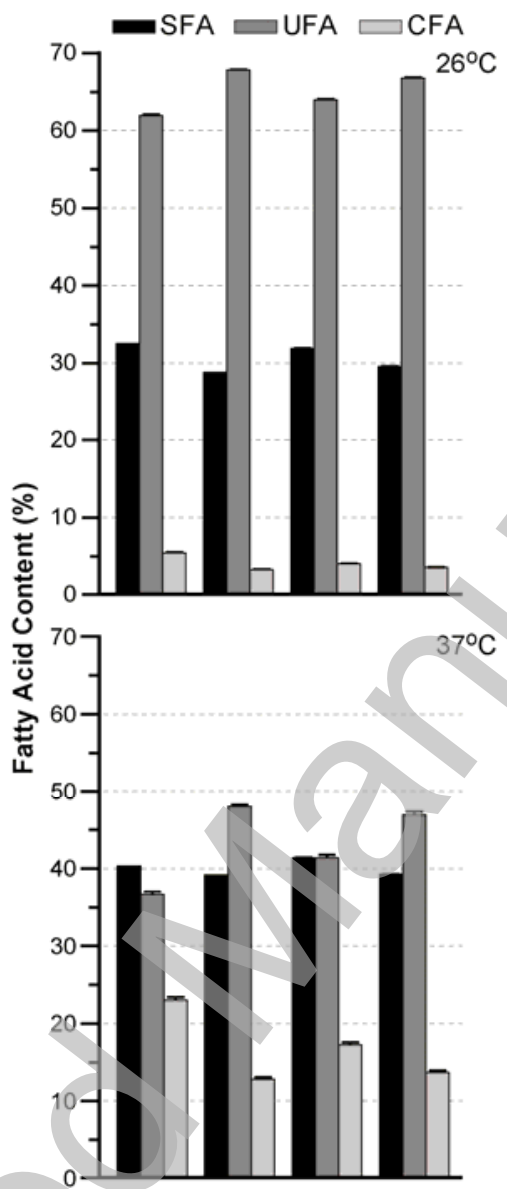

B

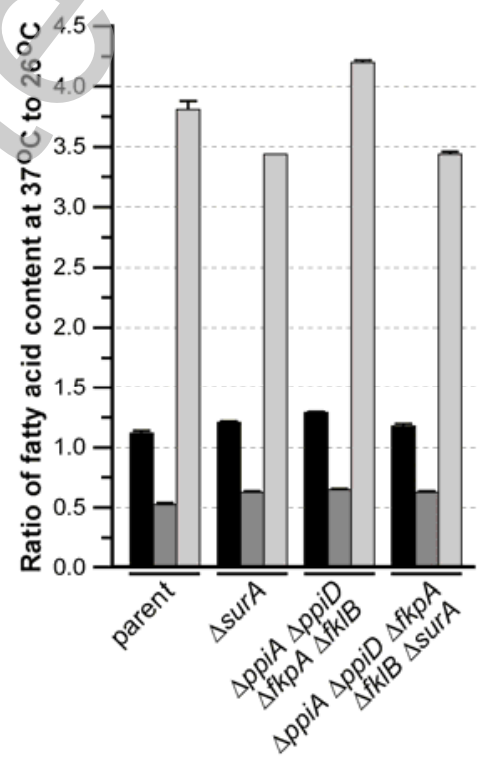


Figure 8: Obi et al., 2011

A

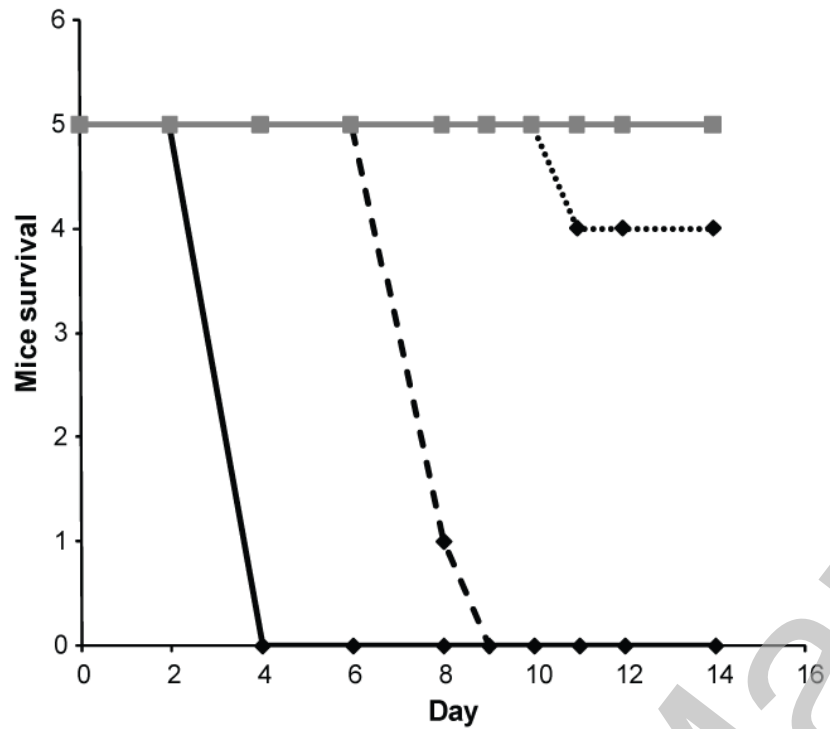

- parent $\left(10^{6}\right)$

$\longrightarrow$ parent $\left(10^{5}\right)$

$\bullet \bowtie$ parent $\left(10^{4}\right)$

$\longrightarrow \Delta \operatorname{surA}\left(10^{6}\right)$

$-x-\Delta \operatorname{surA}\left(10^{5}\right)$

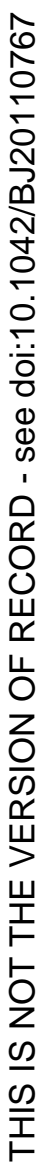

••x.• $\triangle \operatorname{surA}\left(10^{4}\right)$

$-\Delta p p i A \Delta p p i D \Delta f k p A \Delta f k I B\left(10^{6}\right)$

- $\triangle p p i A \Delta p p i D \triangle f k p A \Delta f k l B\left(10^{5}\right)$

- $-\Delta p p i A \Delta p p i D \Delta f k p A \Delta f k I B\left(10^{4}\right)$

- - ppiA $\triangle p p i D \triangle f k p A \Delta f k l B \Delta s u r A\left(10^{6}\right)$

- $\triangle p p i A \Delta p p i D \triangle f k p A \Delta f k l B \Delta s u r A\left(10^{5}\right)$

$\because \bullet$ ppiA $\triangle p p i D \triangle f k p A \Delta f k l B \Delta \operatorname{surA}\left(10^{4}\right)$

B

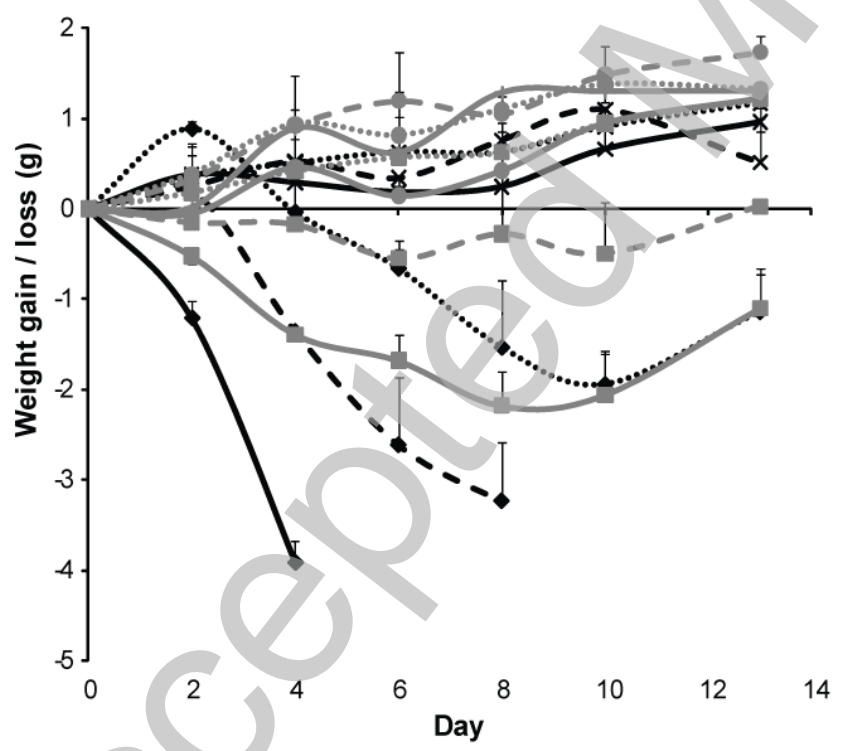

